\title{
Influence of ovarian hormones on value-based decision-making systems: Contribution to sexual dimorphisms in mental disorders
}

\author{
Aiste Ambrase ${ }^{\mathrm{a}, \mathrm{b}, 1}$, Carolin A. Lewis ${ }^{\mathrm{a}, \mathrm{c}, \mathrm{d}, 1}$, Claudia Barth ${ }^{\mathrm{e}}$, Birgit Derntl ${ }^{\mathrm{a}, \mathrm{b}, \mathrm{f}, \mathrm{g}, *}$ \\ ${ }^{a}$ Department of Psychiatry and Psychotherapy, University of Tuebingen, Tübingen, Germany \\ ${ }^{\mathrm{b}}$ International Max Planck Research School for Cognitive and Systems Neuroscience, University of Tübingen, Tuebingen, Germany \\ ${ }^{\mathrm{c}}$ Emotion Neuroimaging Lab, Max Planck Institute for Human Cognitive and Brain Sciences, Leipzig, Germany \\ d International Max Planck Research School on Neuroscience of Communication: Function, Structure, and Plasticity, Leipzig, Germany \\ ${ }^{\mathrm{e}}$ Norwegian Centre for Mental Disorders Research, Institute of Clinical Medicine, University of Oslo, Oslo, Norway \\ ${ }^{\mathrm{f}}$ TübingenNeuroCampus, University of Tübingen, Tübingen, Germany \\ ${ }^{\mathrm{g}}$ LEAD Research School and Graduate Network, University of Tübingen, Tübingen, Germany
}

\section{A R T I C L E I N F O}

\section{Keywords:}

Estradiol

Progesterone

Decision making

Reward processing

Menstrual cycle

Dopamine

Serotonin

Substance use disorder

Depression

\begin{abstract}
A B S T R A C T
Women and men exhibit differences in behavior when making value-based decisions. Various hypotheses have been proposed to explain these findings, stressing differences in functional lateralization of the brain, functional activation, neurotransmitter involvement and more recently, sex hormones. While a significant interaction of neurotransmitter systems and sex hormones has been shown for both sexes, decision-making in women might be particularly affected by variations of ovarian hormones. In this review we have gathered information from animal and human studies on how ovarian hormones affect decision-making processes in females by interacting with neurotransmitter systems at functionally relevant brain locations and thus modify the computation of decision aspects. We also review previous findings on impaired decision-making in animals and clinical populations with substance use disorder and depression, emphasizing how little we know about the role of ovarian hormones in aberrant decision-making.
\end{abstract}

\section{Introduction}

We make choices by assigning subjective value to options available for us multiple times a day. However, numerous neuropsychiatric disorders which display a prominent sexual dimorphism, such as major depression and addiction, suffer from aberrant decision-making as a core feature (Wittchen et al., 2011). On the neural level, decision processes may be inappropriately affected by changes in neurotransmitter systems due to the disorder. In addition, further modulations of the decision-making processing may occur due to the interaction between the neurotransmitter systems and sex hormones, which has been shown for both women and men (Barth et al., 2015). For women in particular, decision-making processes may be affected by systematic variation of ovarian hormones - both monthly as well as over the course of their reproductive years. This may pose unique challenges to decision-making in healthy and clinical populations of women.

Healthy women and men exhibit differences in behavior when making value-based decisions, although usually the effect sizes found in the studies addressing these sex differences are small (for a meta-analysis, please see Nelson, 2016). For instance, while men are biased towards maximizing rewards even if this strategy is not optimal, women prefer frequent but smaller rewards. Relative to men, women are also more sensitive to information on foregone rewards as they tend to regret suboptimal changes in their decision-making strategy (Byrne and Worthy, 2015; Cornwall et al., 2018). In a similar fashion, loss of reward during the previous decision increases women's tendency to choose safe options (Lee et al., 2009). Women and men are also differently affected by stress during decision-making: albeit similar increase in cortisol levels following stress induction, women were slower than men in reward collection rate, decision speed and had lower total earnings when stressed (Lighthall et al., 2012). Combined with sexual dimorphisms in prevalence for mental disorders, these differences might have a substantial effect on one's quality of life.

Various hypotheses have been proposed to explain these behavioral sex differences in value-based decision-making. On a neural level, sexual dimorphisms may arise (i) from sex differences in functional lateralization of the brain areas involved in decision-making circuits,

\footnotetext{
* Corresponding author at: Department of Psychiatry and Psychotherapy, University of Tübingen, Tübingen, Germany.

E-mail address: birgit.derntl@med.uni-tuebingen.de (B. Derntl).

${ }^{1}$ Shared first authorship.
} 
A

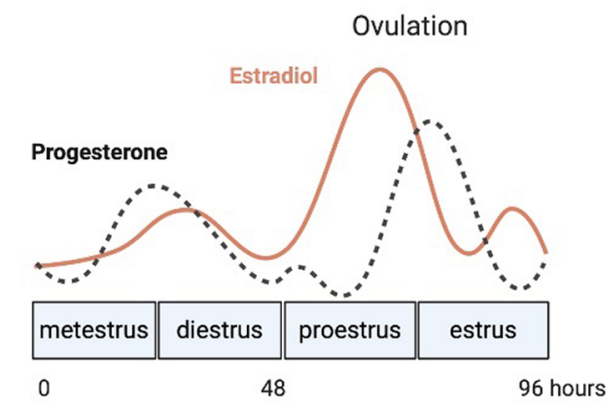

B Human Menstrual Cycle

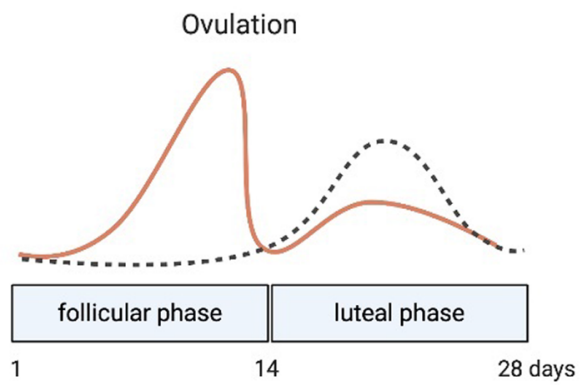

C

Impact of High Estradiol Levels on Decision-making

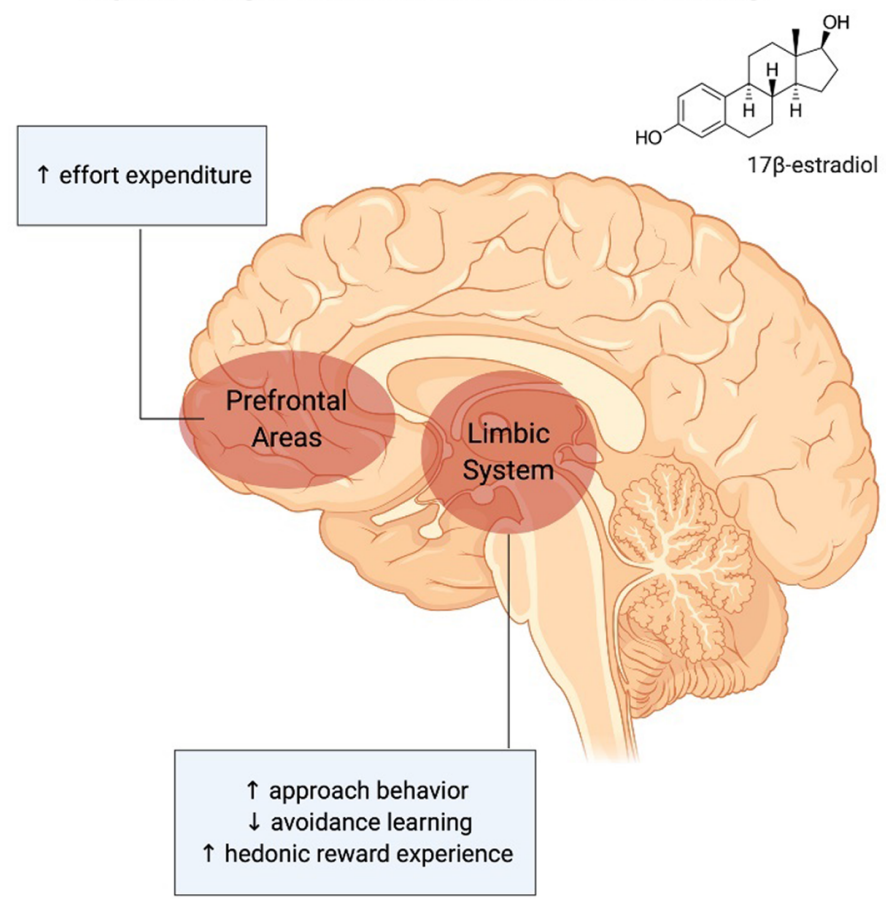

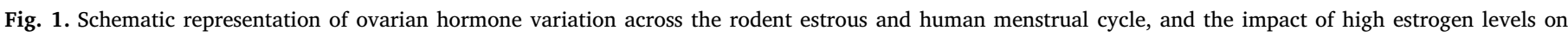

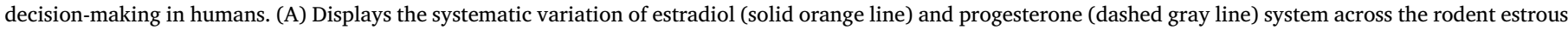

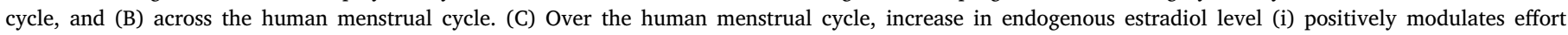

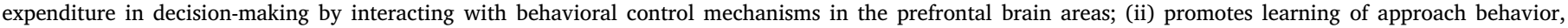

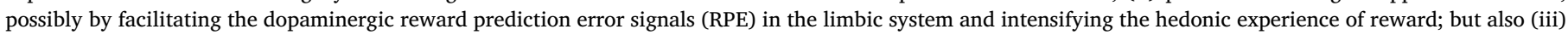

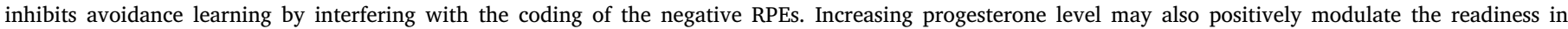
expending effort and behavioral control over the menstrual cycle, but more research is needed.

like the ventromedial prefrontal cortex (VMPFC) and the amygdala (Tranel et al., 2005; Tranel and Bechara, 2009; Sutterer et al., 2015); (ii) from sex differences in typical functional activation of the amygdala and orbitofrontal cortex (OFC) (Sacher et al., 2013); or (iii) from sex differences in the neuroanatomical basis of the behavioral inhibition (BIS) and behavioral activation systems (BAS) (Li et al., 2014) as well as (iv) dissimilar involvement of the dopaminergic and stress systems in decision-making for the sexes (Georgiou et al., 2018). Moreover, current research in clinical samples (Becker and Chartoff, 2019) - concerning development of disorders, prevalence and response to treatment - suggests a significant role for sex hormones as modulators to account for these behavioral sex differences both in mental health and disease.

Emerging evidence suggests effects of ovarian hormones, such as estradiol and progesterone, on value-based decision-making in women. Estradiol and progesterone vary across women's lifespan with increasing levels during puberty and pregnancy, withdrawal states during postpartum and during the transition to menopause, and variable levels across the menstrual cycle. How the variation impacts decision-making is still understudied. This is a critical research gap as such knowledge is crucial to understand sex differences and the effects of female-specific hormonal transition phases on prevalence, course, and treatment response in neuropsychiatric pathologies. So far, most human studies focused on menstrual cycle effects on decision-making.

In this review, we aim to provide an overview of the basic principles of decision-making processing and to highlight the interactions between the two major neurotransmitter systems involved in decision-making dopamine and serotonin - and their hormonal modulators - estradiol and progesterone - in females, combining the knowledge from both animal and human literature. Where possible, we discuss findings on modulation by estradiol and progesterone, however, studies assessing the effects of the latter are even more scarce than those assessing the effects estradiol, both in animal and human literature. We will discuss evidence on the modulatory effects of ovarian hormones on decisionmaking in both healthy females and females suffering from substance use disorder and unipolar depression. Both disorders have been linked to aberrant neurotransmission in the brain. Substance use disorder can be traced back to the impairments of the dopaminergic signaling (for review see Volkow et al., 2004); and depression may involve aberrant serotonergic neurotransmission (for review see Dell'Osso et al., 2016). Although substance use disorder is more prevalent in men, women are more affected in terms of addictive attributes and relapse rates (for reviews see Becker, 2016; Becker and Chartoff, 2019). Depression is the most prevalent neuropsychiatric disorder in women worldwide (Kuehner, 2017).

\subsection{Variation of ovarian hormones across the menstrual cycle}

Modulatory effects of ovarian hormones in decision-making have been investigated mostly across the natural menstrual cycle as it provides (i) a natural model of investigating hormonal influences in women, as well as (ii) convenience, financial advantages and proper ethical considerations. Very few studies measured interactions between ovarian hormones and behavioral changes in decision-making during other significant hormonal transitions, like puberty (Op de Macks et al., 2016), pregnancy and postpartum period (Hellgren et al., 2012) or menopause (Thomas et al., 2014). Therefore, in this review, we will mainly focus on the effects of the menstrual cycle in decision-making.

Across the menstrual cycle, ovarian hormones show characteristic variation in the course of 28 days on average (Bull et al., 2019). In the follicular phase, covering onset of menses and ovulation, estradiol levels slowly rise and surge shortly before ovulation, while progesterone 
A

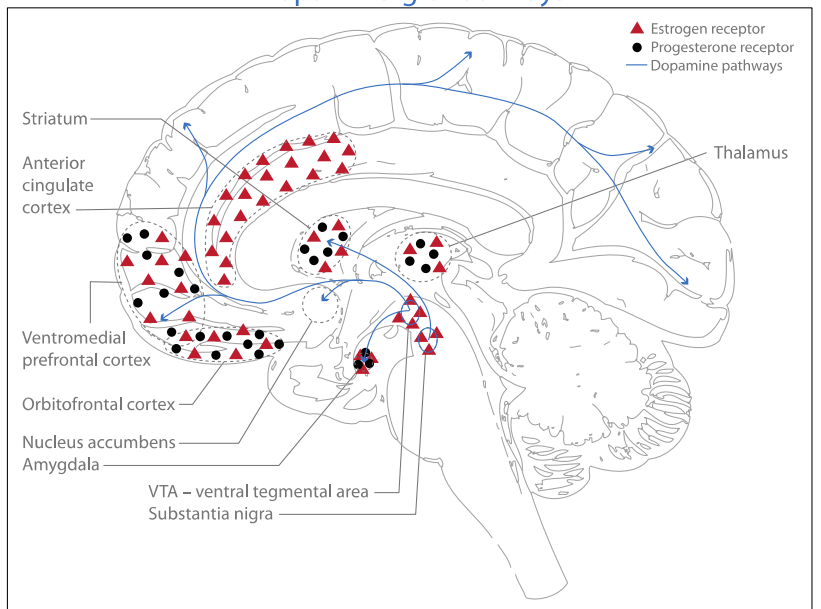

B B Serotonergic Pathways

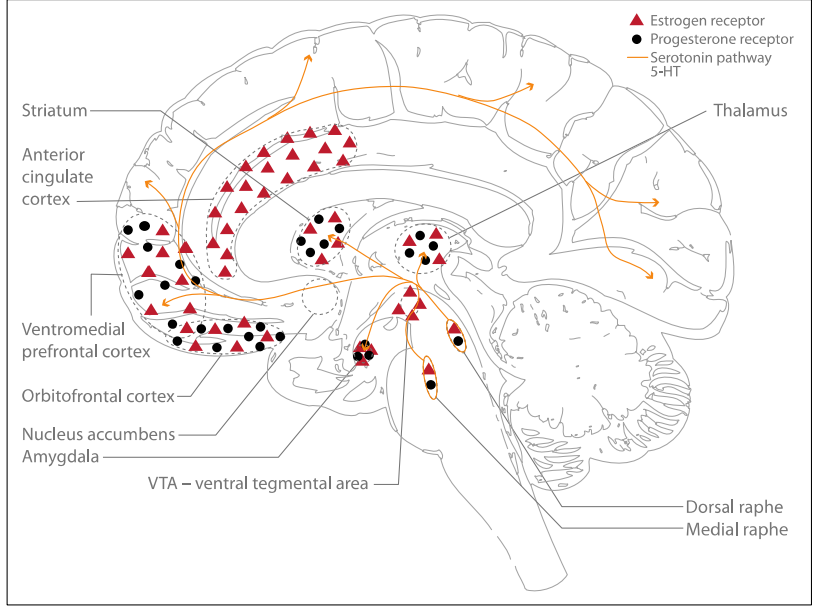

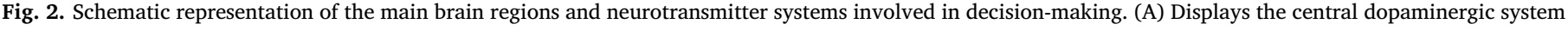

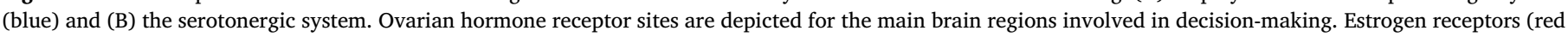

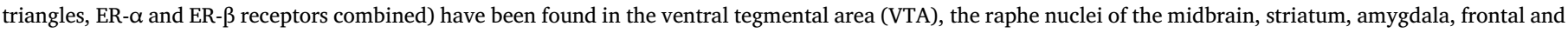

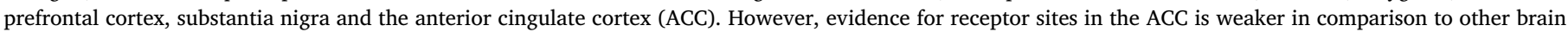

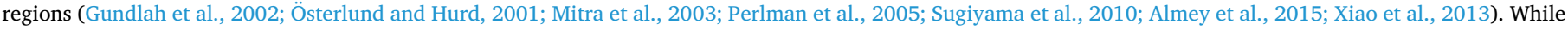

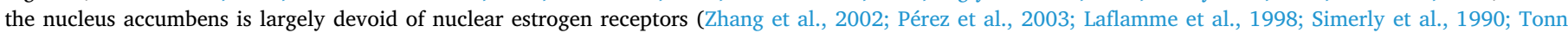

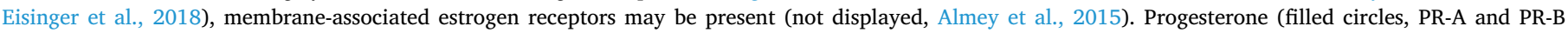

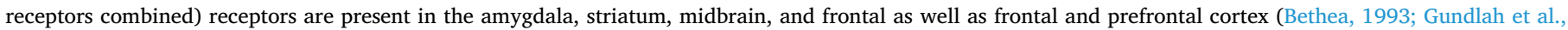

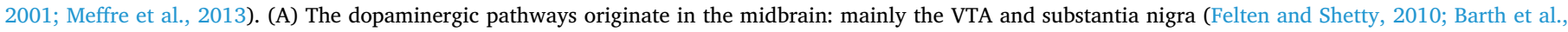

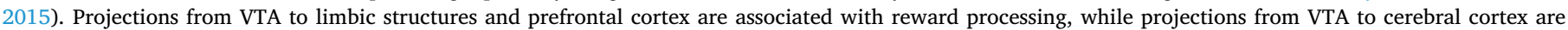

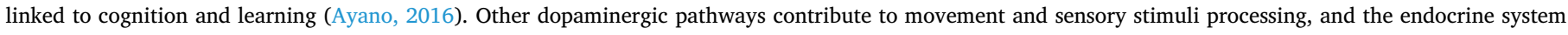

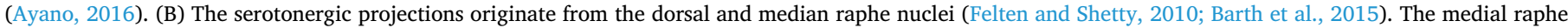

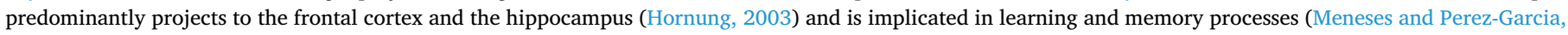

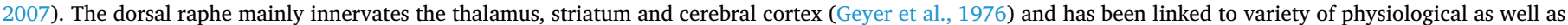
cognitive functions (Meneses, 1999). Figure adapted with author's permission from Barth et al. (2015).

levels remain low. After ovulation, in the luteal phase, progesterone levels increase gradually, with a mid-luteal peak in parallel to a second blunted peak of estradiol. Preceding menses, estradiol and progesterone levels rapidly withdraw (Sundström Poromaa and Gingnell, 2014). Please see Fig. 1 for an illustration of rodent estrus (A) and human menstrual (B) cycle-related hormonal variation as well as impact of high estradiol levels on decision-making (C). For a summary on how each included study assessed the menstrual cycle phase in humans please see supplementary materials (Table S1).

\subsection{Mechanisms of interaction between ovarian hormones, brain function and neurotransmitter systems}

The two main ovarian steroid hormones, estradiol and progesterone, are master regulators of functions such as mood, cognition and arousal, which extends their role far beyond the reproductive tract (Brinton et al., 2015). The ability of estradiol and progesterone to influence emotional and cognitive functioning is largely by modifying gene expression via classical genomic as well as non-genomic membrane-associated receptors in the human brain. Activated by estradiol, nuclear estrogen receptors - ER- $\alpha$ and ER- $\beta$ - promote the expression of nuclear encoded genes that are required for cell growth, development, differentiation, and homeostasis (Marino et al., 2006). Progesterone also impacts genomic gene expression by binding to its nuclear receptors PR-A and PR-B (Brinton et al., 2008). Both ER and PR receptors are highly expressed in brain regions involved in emotion regulation and cognitive control, such as the hippocampus, amygdala and prefrontal cortex (Brinton et al., 2015; Mitra et al., 2003). Apart from classic ER/ PR-dependent genomic regulation, estradiol and progesterone can also bind to transmembrane $\mathrm{G}$ protein-coupled receptors and directly trigger non-genomic rapid signaling pathways such as mitogen-activated protein kinase (MAPK) and phosphatidylinositol-3 kinase (PI3K) cascades
(Mannella and Brinton, 2006). Among others, these signaling cascades have been demonstrated to be neuroprotective by promoting cell growth, proliferation and survival as well as apoptosis (Cao et al., 2019; Kasubuchi et al., 2017). While genomic actions of estradiol and progesterone are relatively slow, minutes to hours, non-genomic membrane-associated signaling is much faster, requiring only milliseconds to seconds (Cornil et al., 2006). Rapid non-genomic actions of estrogen are mediated by membrane-associated ER- $\alpha$ and ER- $\beta$ as well as the Gprotein coupled estrogen receptor (GPER1, Srivastava and Evans, 2013). While the motivational brain circuitry is largely devoid of nuclear estrogen receptors (Tonn Eisinger et al., 2018), membrane-associated ERs are expressed in the dorsal striatum and nucleus accumbens as well as in the prefrontal cortex and the hippocampus (Almey et al., 2015), providing a potential mechanism for estradiol's rapid effects on cognition. For instance, GPER1 rapidly regulates hippocampal dendritic morphology and synaptic plasticity, and may subsequently enhance learning and memory (for review see Alexander et al., 2017). Besides rapid estrogenic actions, progesterone also mediates a wide range of physiological processes through non-classical signaling pathways via various non-nuclear progesterone receptors including membrane-associated receptors and the distinctly different progesterone receptor membrane component 1 (PGRMC1, for review see Garg et al., 2017). Yet, genomic and non-genomic actions of estradiol and progesterone are highly intertwined, leaving a less clear-cut distinction as was first thought (Vasudevan and Pfaff, 2008).

Besides the activation of their own receptors, ovarian hormones can also act on other receptor types including $\gamma$-aminobutyric acid (GABAA) (Gulinello et al., 2001), N-methyl-d-aspartate (NMDA) (Foy et al., 1999; Kow and Pfaff, 2018), serotonin (Sumner and Fink, 1998; Borrow and Cameron, 2014) and dopamine receptors (Becker, 1990a, 1990b; Diekhof, 2018). Ovarian hormones can modulate the responsiveness of postsynaptic receptors (Maejima et al., 2013; Yankova et al., 2001) or 
the presynaptic release of neurotransmitters (Yokomaku et al., 2003), thereby pivotally shaping neurotransmission (for review see Barth et al., 2015).

The action of ovarian hormones in the brain is largely dependent on the specific location of the receptors (McEwen and Alves, 1999). For instance, estradiol and progesterone receptors are densely present along the midbrain dopaminergic neurons and other areas related to the reward systems, such as the amygdala and striatum (see Fig. 2A; Lammers et al., 1999; Creutz and Kritzer, 2004; Vandegrift et al., 2017; Willing and Wagner, 2016). Considerable evidence from animal and human studies suggests that the mesolimbic and mesocortical dopamine systems are susceptible to circulating ovarian hormones. Particularly estradiol is known to exert complex modulatory control over dopamine, mainly enhancing its neurotransmission. Animal studies indicate that estradiol may enhance dopaminergic activity by modulating dopamine synthesis, release and turnover, and the basal firing rate of dopamine neurons (Xiao and Becker, 1994; Pasqualini et al., 1995; Becker, 1990a, 1990b). The effects of estradiol on dopamine function may, however, be sexually dimorphic as well as regionally specific and time-dependent. For instance, ovariectomized rats showed a significant decrease in striatal dopamine (D2) receptor binding in the caudal striatum $30 \mathrm{~min}$ after a single injection of estradiol benzoate (Bazzett and Becker, 1994). This was not the case for castrated rats: striatal D2 receptor binding significantly increased in the rostral striatum four hours after the injection. After two weeks of chronic estradiol treatment, the density of dopamine (D1) receptors significantly increased in ovariectomized rats (Lévesque et al., 1989). This effect was lost when treatment was initiated two weeks or later after ovariectomy. In humans, women have generally higher presynaptic dopamine synthesis capacity in the striatum compared to men (Laakso et al., 2002), while men have more basal dopamine release in multiple regions of the striatum compared to women (Munro et al., 2006). In addition, while women may have lower $\mathrm{D} 2$ receptor affinity than men, striatal D2 receptor density and binding potential seem to decline with age faster in men than in women (Pohjalainen et al., 1998). In sum, estradiol seems to increase the activity and density of D1 receptors (Auger et al., 2001; Lévesque et al., 1989), and may in turn reduce the affinity of D2 receptors (Lévesque and Di Paolo, 1989; Becker, 1999). This estrogenic effect on dopamine receptors seems to vary across the menstrual cycle. Studies in rats indicate that striatal D1 receptors fluctuate across the estrous cycle, with highest density during diestrus. Further, menstrual-cycle-dependent variations in D2 receptor availability have also been reported in nonhuman primates (Czoty et al., 2009).

However, variations in estradiol levels across the menstrual cycle do not happen in isolation, but rather in parallel with progesterone and its neuroactive derivative allopregnanolone. From the follicular to the luteal phase, both increases in progesterone and decreases in estradiol have been associated with activity changes in brain areas linked to reward processing such as the prefrontal cortex (PFC), limbic and striatal regions (Dreher et al., 2007; van Wingen et al., 2008; Ossewaarde et al., 2011). It has been suggested that progesterone may decrease dopamine release or synthesis (Diekhof et al., 2018). However, progesterone's impact on dopaminergic transmission seems dependent on baseline estradiol levels as stimulating effects on dopamine release were found in rats which were pre-exposed with estradiol (Becker, 1990a, 1990b). Allopregnanolone, a neuroactive steroid, which can be synthesized from steroid hormone precursors, such as progesterone, or synthesized de novo from cholesterol (Walton \& Maguire, 2019) has been shown to modulate cognitive functions (Marx et al., 2009), likely due to modulatory effects on GABAergic neurotransmission (Majewska et al., 1986). Just like progesterone and its derivative, GABA levels increase from the follicular to the luteal phase (Epperson et al., 2002).

Ovarian hormones also interact with the serotonergic system. Serotonergic neurons are densely expressed in the dorsal and medial raphe nuclei (DRN, MRN) of the midbrain with ascending fibers projecting to areas rich in ovarian hormone receptors such as the frontal cortex, striatum, thalamus, amygdala, hypothalamus and hippocampus (see Fig. 2B; for review see Barth et al., 2015). Estradiol modulates the serotonergic system from the level of serotonin synthesis and degradation to binding and reuptake (for review see Del Río et al., 2018). However, describing the effects of estradiol on serotonin as clearly excitatory or inhibitory is challenging. For instance, while most studies observed that estradiol increases serotonin transporter expression in many brain areas, some studies report a decrease in serotonergic activity after estradiol treatment in a dose-dependent manner (for review see Thibeault et al., 2019). In contrast to the effect of estradiol, progesterone seems to clearly increase serotonergic neurotransmission by regulating the expression of serotonin-related genes and proteins (for review see Barth et al., 2015).

\section{Effects of sex hormones on neural decision-making circuits}

Decision-making can be divided into several processes that are inherently intertwined due to their neurobiological underpinnings and scientific paradigms used to investigate them. Nevertheless, relying on a theoretical division of decision-making processes can be useful in order to highlight process-specific effects of systematic variation of ovarian hormones. As a guideline for our review, we thus decided to follow the model from Rangel et al. (2008), which postulates five main computational processes of decision-making. These processes include (i) representation of the decision problem, including internal and external states (e.g. environmental factors) that provide information on the decision at hand - here called prediction cues; (ii) evaluation of available action choices by assigning a value to them - here termed valuation; (iii) action selection based on the valuation process - here termed action selection and execution; (iv) outcome valuation; (v) and learning - which we put together based on the available literature. These processes are neurobiologically well-described and can be investigated with specified paradigms. Every "decision process" will start with the neurobiological mechanism, followed by experimental results from animal studies which will be complemented by the available findings from humans. Ovarian hormones may differentially affect all of these decision-making processes in females by interacting with neurotransmitter systems at functionally relevant brain locations, and thus modify the computation of the relevant decision aspects, such as decision valence, choice value and its modulators, such as risk, uncertainty, temporal delay, hedonia, and motivation. As we aim at highlighting the impact of ovarian hormones on the decision-making processes particularly in females, we have put a specific emphasis on reporting those studies that either directly assessed endocrinological levels or used a study design that allowed inferences about hormonal states (please see also supplementary Table S1 for a summary on how each included study assessed the menstrual cycle phase in humans).

\subsection{Decision process: Prediction cues}

\subsubsection{The neurobiological mechanism}

Recognition of the decision problem at hand might begin with directing attention to valenced cues which suggest whether rewards or punishments are to be expected. The majority of research in this area has focused on positively valenced decision problems, i.e. measuring reward sensitivity and salience signals, and their impact on reinforced learning in animals as well as humans (for review see O'Doherty et al., 2017). Negatively valenced decision problems that use punishment as a reinforcer have been scarcely used in previous research, therefore, brain signals related to punishment are less well understood. While learning will be addressed later on, in this section we will focus on recognition of cue valence and prediction of decision outcome.

Reward prediction cues are coded by the midbrain dopamine neurons in the ventral tegmental area (VTA), which projects the signal further to the nucleus accumbens (NAcc) in the ventral striatum and higher cortical areas (Schultz, 1997; Dichter et al., 2012; Krolick et al., 
2018), and are also coded in the serotonergic neurons in the DRN (Cohen et al., 2015). The dopaminergic and the serotonergic systems are assumed to interact in reward prediction coding as some of the DRN neurons terminate in the VTA and the NAcc (Liu et al., 2014; Zhou et al., 2015). Reward prediction signals are relayed to prefrontal and cingulate cortex via dopaminergic projections from the striatum (Haber and Knutson, 2010).

Punishment prediction cues have been shown to mainly suppress the basal activity of the VTA dopamine neurons while simultaneously exciting GABAergic neurons in this region (Cohen et al., 2012). Animal studies have also shown that the central area of the ventral striatum is dedicated for processing aversive stimuli (for review see Saga and Tremblay, 2017), the same region has also been shown to react to aversive stimuli in humans (Palminteri et al., 2015; for a review see Delgado et al., 2008).

\subsubsection{Effects of ovarian hormones on prediction cues: Evidence from animals}

Animal studies have indicated that estradiol modulates the signaling in the VTA-NAcc pathway and in the DRN, affecting perception of reward cues. Preliminary evidence suggests that elevated estradiol corresponds with enhanced responses of dopaminergic VTA neurons thereby increasing their sensitivity to reward cues such as ethanol or cocaine (Zhang et al., 2008; Vandegrift et al., 2017). Reward prediction signals in the NAcc are also believed to be affected by concentration changes of estradiol. As reviewed by Yoest et al. (2018), estradiol can affect dopamine release in the NAcc by either (i) increasing the firing rates of VTA dopaminergic neurons (Calipari et al., 2017), (ii) directly influencing dopamine reuptake in the NAcc (Thompson and Moss, 1994) or (iii) facilitating dopamine release in the NAcc by binding to transmembrane G protein-coupled estrogen receptors (Yoest et al., 2014).

Although not directly assessed in the decision-making domain, evidence suggests a positive effect of estradiol on the serotonergic neurotransmission in the DRN as well: estradiol treatment, unopposed by progesterone, of ovariectomized female rats increased serotonin synthesis in caudal DRN and correlated with decreased anxiety-like behaviors (Hiroi et al., 2006, 2016). Felton and Auerbach (2004) found higher extracellular serotonin level during the proestrus as compared to the estrus phase.

Based on these findings, one can hypothesize that the interaction of the dopaminergic and serotonergic systems in cue recognition may increase affective bias formation towards positive cues or decrease bias formation towards negative cues when circulating estradiol is high.

\subsubsection{Effects of ovarian hormones on prediction cues: Evidence from humans}

Based on human brain imaging studies, attention to reward cues as well as value ascription may be affected by varying levels of estradiol and progesterone, and their ratio. However, the direction of this effect might also depend on the type of stimuli as well as valence of information presented.

In a monetary reward task, the ventral striatum showed stronger activation to rewards in the late luteal phase as compared to the late follicular phase (Ossewaarde et al., 2011). Using electroencephalography (EEG) and a monetary incentive delay task, Banis and Lorist (2017) found larger cue-related theta power increases in potential reward trials versus no reward trials during the late luteal phase as compared to the follicular phase, similar to the findings reported by Ossewaarde et al. (2011).

Frank et al. (2010) observed increased functional activation in the NAcc, amygdala and hippocampus during the late follicular phase when comparing presentation of pictures with high caloric food vs. neutral pictures. However, the same experiment showed that functional activation of the OFC was greater in the luteal phase as compared to follicular when looking at high caloric in comparison to low caloric food pictures (Frank et al., 2010). In another experiment, when presented with food pictures, participants in a fasting condition showed a negative association between functional activation of the right fusiform gyrus (part of visual attention circuit) and endogenous estradiol, indicating reduced sensitivity to reward cues when estradiol was high (Alonso-Alonso et al., 2011).

Based on these findings, it has been recently suggested that the effects of estradiol on reward processing in humans might not fully mirror the findings observed in rodent models (Diekhof, 2018). One of the factors contributing to this inconsistency of results may be differences in research paradigms used in animals and humans to study reward sensitivity. Animals usually undergo a training phase in these paradigms and are conditioned to recognize reward cues, while human experiments do not include this step. In fact, animal research has shown that in untrained animals high estradiol phases coincide with a decrease in eating behavior, reduced meal sizes and increased bias towards lower effort rewards (for review see Yoest et al., 2014), indicating that processing of rewards in more natural experimental conditions might be affected differently by varying levels of ovarian hormones.

\subsection{Decision process: Valuation}

\subsubsection{The neurobiological mechanism}

The neurophysiological valuation mechanism is assumed to be based on cost-benefit weighting, resulting in the subjective value parameter for each available choice alternative (Basten et al., 2010). Risk, uncertainty, temporal delay, as well as physical or even cognitive effort in this process are considered as costs (Westbrook et al., 2019; Chong et al., 2017; Croxson et al., 2009), while physical and social rewards, like food, sex or money, as well as the hedonic experience from receiving the reward constitute benefits. All these decision variables might impact the calculation of subjective value (for review see Khani and Rainer, 2016).

The valuation system in the brain utilizes the dopaminergic and serotonergic reward prediction signals from the ventral striatum (Rushworth et al., 2012; Tobia et al., 2014) and integrates them with subjective preference, or else 'liking' information within the VMPFC (Bouret and Richmond, 2010; Fischer and Ullsperger, 2017) via the glutamatergic medial OFC and basolateral amygdala connection (Malvaez et al., 2019). The serotonergic signals, relayed from the DRN in the midbrain to frontal cortical areas, have been primarily associated with formation of 'liking' (Dölen et al., 2013; Li et al., 2016) and form the basis of subjectivity in the valuation signals. The cingulate cortex tracks the cost-benefit balance for the choice options (Bartra et al., 2013) and has been suggested to generate effort expenditure signals by utilizing dopamine neurotransmission in this area (Wang et al., 2017). Studies in monkeys have shown that electrical stimulation of the anterior cingulate cortex (ACC) increased their avoidance behavior, most probably via the direct connection to the ventral striatum (Amemori and Graybiel, 2012).

\subsubsection{Effects of ovarian hormones on valuation: Evidence from animals}

While sex differences in the valuation behavior of integrating costs and benefits have been investigated to some extent in animals (for review see Orsini and Setlow, 2017), direct evidence on the modulatory effects of ovarian hormones on the valuation mechanism is lacking. Orsini et al. (2016) and Georgiou et al. (2018) did not observe a significant effect of estrous cycle (Fig. 1A) phase in female rats in risktaking behavior. Uban et al. (2012) investigated the effect of ovariectomy and estradiol administration on effort-based decision-making. While ovariectomy increased the preference for larger but more physically effortful rewards, high estradiol decreased this preference. Notably, the authors also showed that estradiol affects decision-making via ER- $\alpha$ and ER- $\beta$, albeit in opposing directions, and report no effect of estrous cyclicity on decision making. Wallin-Miller et al. (2017) reported that ovariectomized rats treated with estradiol exhibited a trend 
towards a greater preference for larger, uncertain rewards than ovariectomized rats without estradiol treatment. While the reported results are inconclusive, the studies differ in many aspects and estradiol may modulate decision-making for larger rewards differently when risk or effort is linked to that reward. Also, estrogen receptor types involved may exert different effects. More research is needed to further elucidate the role of estradiol on valuation mechanisms.

\subsubsection{Effects of ovarian hormones on valuation: Evidence from humans}

Generally, women prefer safer yet smaller rewards in gambling tasks as opposed to men. This finding is consistent across different age ranges and has been replicated in animals (for reviews see van den Bos et al., 2013; Orsini and Setlow, 2017). Self-report data indicated that risk-taking behavior in women significantly rises when estradiol is high (Sukolová and Sarmány-Schuller, 2011). Ovulating women were also more likely to choose a risky over a safe option and showed reduced loss aversion compared to women in other menstrual cycle phases as well as men. In addition, women in their ovulatory phase were also more successful in maximizing their wins in a gambling task relative to other menstrual cycle phases (Lazzaro et al., 2016).

Other studies, however, did not report an effect of menstrual cycle phase on risk-taking behavior (Reavis and Overman, 2001; van den Bos et al., 2007). Hence, it is currently unclear whether female risk-taking behavior is in fact influenced by ovarian hormone variation.

For instance, reported sex differences in risk-taking behavior are already present in prepubescent children before age-related changes in sex hormone levels (Overman et al., 2004; Crone et al., 2008; van den Bos et al., 2013). Age-related differences in estradiol also could not explain changes in risk-taking behavior in women aged 8-28 years in a longitudinal study by Peper et al. (2018). While Derntl et al. (2014) also did not find a general effect of menstrual cycle phase on risk-taking behavior, higher progesterone in the luteal phase correlated with increased risk-taking in women.

Taken together, these results do not indicate a clear interaction between ovarian hormones and the valuation of benefits and costs - a process which is mainly dependent on higher cortical areas. In rodents, a non-linear relationship between estradiol and risk-taking behavior may be proposed, although more studies are necessary to draw firm conclusions. In humans, however - when an effect was observed - both estradiol and progesterone were positively related to increased risktaking.

One major limitation in discussing effects of ovarian hormones on valuation processes is the lack of variety in experimental paradigms. Different benefit-cost combinations - utilizing not only risk but also uncertainty, physical and mental effort, primary and secondary punishment - could be used to design more insightful animal and human studies, additionally controlling for valence and primary/secondary reward distinction. Furthermore, risk-taking behavior in women as well as men is largely affected by endogenous and exogenous testosterone and its ratio with steroid cortisol (Stanton et al., 2011; Mehta et al., 2015). This opens another question on what the effects of ovarian hormones are when the effects of testosterone are simultaneously tested, as testosterone is aromatized to estradiol in women (Azcoitia et al., 2011).

\subsection{Decision process: Action selection and execution}

\subsubsection{The neurobiological mechanism}

The action selection mechanism and the vigor to which the action is executed are related to the concept of 'wanting', that is, choice motivation and incentive salience to stimuli (Berridge and Robinson, 1998). When it comes to action, both appetitive and aversive outcomes can be actively pursued (i.e. 'go to receive reward') or avoided (i.e. 'go to avoid punishment') as well as passively pursued (i.e. 'nogo to receive reward') or avoided (i.e. 'no-go to avoid punishment'). The concept of 'wanting' contributes to the choice between approach or avoidance behavior (Guitart-Masip et al., 2014; Boureau and Dayan, 2011).

It has been suggested that value information from the valuation circuit is relayed to the OFC for choice selection (Padoa-Schioppa and Conen, 2017). From the OFC, the ventral striatum receives this topdown signal as well as information on valence from the amygdala. 'Liking' and 'wanting' signals are believed to interact in action selection and contribute to the control of effort expenditure and timing of the action (Miyazaki et al., 2012). The dopaminergic activity in the ACC has been suggested to code effort expenditure signals which further activate action preparation systems via its limbic afferents, while the serotonergic activity in DRN and its projections to OFC and VMPFC the 'liking' mechanism - might control action execution.

The higher serotonergic DRN activity has been related to increased willingness to wait longer for rewards in temporal delay tasks. In these tasks, the reward cue and the acquisition of reward are separated by a predictable or unpredictable period of time, and the more the reward is delayed, the less valuable it becomes, i.e. it is discounted (Ainslie, 1975). Higher serotonergic activity in the DRN, however, is associated with prevention of delay discounting effects by elevating the behavioral control of impulsive reactions to reward cues and enhancing perseverance to pursue the 'wanted' action (Miyazaki et al., 2018; Lottem et al., 2018). Serotonin release has also been associated with processing of aversive events: it has been shown that serotonin-depleted animals show reduced behavioral inhibition in the face of punishing cues and contexts. However, similarly as in delay discounting, it is more likely that the general behavioral control mechanism is affected by serotonin depletion, rather than the processing of punishment (for review see Soubrié, 1986).

To discuss action selection modulation by ovarian hormones we will discuss results from various 'Go/No-Go' tasks and the findings related to the modulation of the dopaminergic and serotonergic systems. Although 'Go/No-Go' tasks with temporal delay could also be discussed along the cost-benefit analysis of the valuation system, they are good indicators of how choice selection is achieved as well as approach/ avoidance strategies selected and controlled, for example, when a 'Go' response has to be withhold and 'No-Go' strategy selected to obtain reward or avoid punishment. Therefore, we will use evidence from these tasks to illustrate the interaction between ovarian hormones and action selection.

\subsubsection{Effects of ovarian hormones on action selection and execution: Evidence from animals}

In a 'Go/No-Go' task with food stimuli, exogenous progesterone application in both male and female rats resulted in a more stable 'No-Go' response when it was required but did not affect the 'Go' response (Swalve et al., 2016). Conversely, the 'No-Go' response for cocaine in a temporal delay task was stronger in female but not male rats when treated with both unopposed progesterone and in combination with atomoxetine, a selective noradrenaline reuptake inhibitor (Smethells et al., 2016). Similarly, progesterone treatment affected female but not male rats in reducing impulsive 'Go' responses to cocaine when 'No-Go' was required, yet no effect of progesterone treatment was found for cocaine self-administration (Swalve et al., 2018). The findings are consistent with effects of varying endogenous levels of progesterone in female rats: cocaine seeking is lowest in a high progesterone state and highest in the low progesterone state (Feltenstein and See, 2007).

Taken together, these results indicate that progesterone differentially reduced impulsive action and impulsive choice for cocaine in female rats but less so in male rats. It was suggested that a potential mechanism of progesterone's actions on drug use might be its ability to reduce impulsive drug seeking (Swalve et al., 2018). Notably, effects of estradiol in temporal delay tasks, however, have not been investigated in rodents. 


\subsubsection{Effects of ovarian hormones on action selection and execution: Evidence from humans}

Using a delay discounting task with monetary rewards, impulsive 'Go' responses decreased significantly with rising estradiol from the menstrual to the late follicular phase, close to ovulation (Smith et al., 2014). This negative correlation was driven by women with assumed lower frontal dopamine levels based on Val158Met polymorphisms in the catechol-O-methyltransferase (COMT) gene. COMT accounts for $60 \%$ of the total dopamine turnover in the PFC (Mannisto and Kaakkola, 1999). Carriers of a met/met allelic variant showed lower COMT activity, enhanced PFC-dependent cognitive function and greater cortical efficiency, indicating optimal dopamine levels in these individuals (Egan et al., 2001; Tunbridge et al., 2006). Based on the findings by Smith et al. (2014), one might speculate that levels of fluctuating estradiol and COMT-genotype-dependent frontal dopamine might influence decision-making in women across the menstrual cycle. A reduction of impulsive responses from the early to the late follicular phase was also demonstrated in women with low trait impulsivity but not in women with high trait impulsivity (Diekhof, 2015). This suggests that the systematic changes of hormonal levels during the menstrual cycle might be more pronounced in individuals with high trait impulsivity.

On the neural level, hormonal variation over the menstrual cycle could also impact functional brain activation. Using a monetary incentive delay task, Bayer et al. (2013) reported that women's right OFC activation was higher while waiting for rewards in the early follicular phase compared to mid-luteal phase, even though no differences in behavior were observed. Furthermore, while waiting for the loss outcome, women had less increase in activation of the ventral striatum and the ACC during the luteal than the early follicular phase (Bayer et al., 2013). Using a monetary reward paradigm, Dreher et al. (2007) found that in the mid-follicular phase, women showed an increased activation of the OFC and the amygdala to uncertain rewards during the reward anticipation period compared to the mid-luteal phase. This finding seems consistent with the evidence from animal literature where progesterone attenuates approach signals when waiting is required, although the exact role of OFC function and its interaction with progesterone has not been studied in humans. Bonenberger et al. (2013), however, did not find any differences in functional brain activation when women were waiting for a reward across the menstrual cycle.

Using an emotional response inhibition task (verbal 'Go/No-Go'), Amin et al. (2006) measured healthy women twice across their individual menstrual cycle to investigate the impact of diverging hormone levels on brain activation. Women showed increased activation in the ACC, dorsolateral prefrontal cortex (DLPFC), and right putamen during response inhibition to positive words in the mid-luteal phase compared with the early follicular phase. Moreover, individual differences in blood-oxygen-level-dependent (BOLD) response during the mid-luteal phase were modulated by levels of estradiol but not progesterone. Estradiol levels correlated positively with BOLD response during response inhibition to positive stimuli, but negatively during response inhibition to negative stimuli. In an EEG study, GriskovaBulanova et al. (2016) found a positive correlation between estradiol and P3 latency (a measure of valuation) in the 'Go' condition, i.e. higher levels of estradiol indicated prolongation of P3 latency in the 'Go' condition. Higher progesterone levels led to a P3 latency shortening in the 'No-Go' condition. The authors suggested that P3 wave latency shortening in the 'No-go' condition resulted from a decrease in dopaminergic tone with increasing progesterone levels, thereby facilitating the 'No-Go' pathway. The positive association between P3 wave latency and estradiol levels in the 'Go' condition could stem from negative effects of estradiol on cognitive control. For instance, Colzato et al. (2010, 2012) found that the late follicular phase was associated with less efficient inhibitory output control (in a stop-signal task) and more efficient inhibitory input control (in a cued target-detection task). Griskova-Bulanova et al. (2016) also found that estradiol was negatively associated with the negative frontal N2 amplitude (a measure of inhibitory response control) both in the 'Go' and the 'No-Go' condition. The authors interpreted this result as mediating effects of estradiol on the serotonin system. Roberts et al. (2008) used a 'Go/NoGo' response inhibition task with male and female faces as stimuli and measured healthy women during the follicular phase and the luteal phase (within-subject design). Here, inferior frontal gyrus activity was reduced during successful inhibitions irrespective of cycle phase, while ACC activity was enhanced for inhibitory errors in the follicular phase. These results indicated a heightened performance monitoring to inhibit a 'Go' response that was specific to male faces. Protopopescu et al. (2005) found OFC activity to be modulated by menstrual cycle phase by using an emotional linguistic 'Go/No-Go' task: specifically, anteriormedial OFC activity for negative stimuli was increased in the late luteal phase and decreased in the late follicular phase. Lateral OFC activity showed an inverse pattern. The OFC plays a major role in modulating primary regions for emotional behavior, including amygdala and hypothalamus (Drevets, 2000; Cavada et al., 2000). Thus, the authors interpreted these results as enhanced top-down modulation of limbic activity in the face of negative stimuli, which is specific to the premenstrual phase, in which the limbic system may be more excitable.

Taken together, the findings from temporal delay and ' $\mathrm{Go} / \mathrm{No}-\mathrm{Go}$ ' tasks suggest that estradiol and progesterone modulate effort expenditure in these paradigms. While animal literature provides insight into positive effects of progesterone in waiting and abstaining from the more intuitive approach strategy ('No-Go to receive reward') most likely by interacting with the serotonergic neurotransmission in prefrontal brain areas, human literature ascribes this role to estradiol. Due to different research approaches used - progesterone treatment in animals versus natural hormonal variation during the menstrual cycle in humans as well as different lengths of estrous vs. menstrual cycle direct comparison between animal and human literature is limited, although increase in progesterone has been shown in more effortful approach strategy during risk-taking behavior in women as well (as discussed in Section 2.2.3: study by Derntl et al., 2014). However, the majority of evidence from human studies suggests that endogenous estradiol is positively related to behavioral control mechanisms in terms of action selection. Selection of an appropriate response to a decision problem (whether it be 'Go' or 'No-Go' response) was better with higher estradiol levels, as shown by findings from temporal delay and risktaking paradigms where estradiol had facilitating effects on approach behavior (Sections 2.2.3 and 2.3.3). Positive correlations between the brain areas associated with choice selection, behavioral control and top-down regulation of the limbic system, like OFC, ACC and DLPFC and increasing estradiol level further support the suggested hypothesis.

\subsection{Decision processes: Outcome valuation and learning}

\subsubsection{The neurobiological mechanism}

Upon presentation of the decision outcome, VTA dopaminergic neurons increase their firing rate if the predicted rewards occur as expected, and this signal is called a positive reward prediction error (RPE). If the reward is lower or undelivered, the firing rate decreases below the basal firing level, indicating a negative RPE. Positive RPE signals are relayed via a direct pathway from the dopaminergic VTA neurons containing dopamine D1-receptors, while a negative RPE is transmitted via the indirect pathway from the dopaminergic neurons containing D2-receptor type neurons in the substantia nigra pars compacta (SNc) (Cox and Witten, 2019; Frank and Hutchison, 2009) to the striatum, NAcc and frontal cortex (Schultz et al., 1997). Midbrain D3receptors have been associated with relearning cue associations with new outcomes, however, the exact role of these receptors is less clear (Groman et al., 2016).

Separate punishment signals have been identified and are believed to be coded by serotonin in multiple brain structures: starting with the punishment prediction error (PPE) in the DRN, as observed in animal 
studies (Nakamura et al., 2008; Cools et al., 2011; Cohen et al., 2015; Matias et al., 2017), and possibly relaying the error signal further to the VTA and lateral habenula (Kumar et al., 2018; Lawson et al., 2014), and the striatum (Moran et al., 2018), as detected in humans.

Learning from decision outcomes is based on these error signals as the valuation system integrates past experiences and updates subjective value computations by implementing working and long-term memory processes (Rangel et al., 2008). Reward reception and the hedonic experience from consumption of rewards (i.e. food or drug) is considered a powerful reinforcer in the learning process (Kringelbach, 2005).

Animal as well as human studies suggest the PFC as the main candidate for updating action and outcome relationship and facilitating flexible learning, while distinct parts of this region contribute to different aspects of learning (Walker et al., 2008; Dalton et al., 2016; Verharen et al., 2020). For example, in a recent rodent study, Verharen et al. (2020) demonstrated that pharmacological impairment of the infralimbic cortex and medial OFC resulted in lower punishment learning rates, impairment of prelimbic cortex and lateral OFC was followed by combined negative effects in reward and punishment learning, and overall PFC impairment reduced learning in general.

\subsubsection{Effects of ovarian hormones on outcome valuation and learning: Evidence from animals}

Reinforcement learning paradigms in animals have been based on appropriate responses (correct physical turn towards reward) and place learning (physical reward placement in the environment) for rewards and associated with brain structures, such as dorsal striatum for response learning and hippocampus for place learning (Shelton et al., 2013). Experiments with response learning in normally cycling and ovariectomized rats have demonstrated that direct administration of estradiol to the dorsal striatum impaired response learning (Davis et al., 2005; Zurkovsky et al., 2007; Wang et al., 2008). Combined with a D2receptor antagonist but not D1-receptor antagonist, chronic estradiol treatment of ovariectomized rats resulted in increased response learning error rates (Daniel et al., 2006). Consistently, there is also evidence from studies on dopamine's interaction with estradiol that chronic estradiol treatment in ovariectomized rats can have downregulatory effects on D2-receptors in the ventral and dorsal striatum and upregulating effects on D3-receptors in the VTA with no effects on D1-receptors (Lammers et al., 1999; Zhou et al., 2002). Taken together, the findings suggest that high doses of estradiol might negatively affect learning processes by possibly acting on negative RPEs.

When it comes to relearning reward cues and the appropriate response, estradiol replacement in ovariectomized rats seems to play a protective role by keeping relearning and reward cue memory processes intact (Lipatova et al., 2014; Anderson and Petrovich, 2015). Combined with antipsychotic drugs, estradiol rapidly facilitated reversal learning in ovariectomized rats in several studies (Arad and Weiner, 2012; Almey et al., 2017), establishing its role in sustaining striatum-based memory processes.

The hedonic experience of rewards - a reinforcer in the learning process - is increased during high estradiol phases in naturally cycling rats and in ovariectomized rats with estradiol replacement, as demonstrated by Bless et al. (1997). Similarly, estradiol replacement in ovariectomized rats with induced anhedonia had positive effects on reducing anhedonia-related behaviors (Schiller et al., 2013). However, how this estradiol-modulated increase in hedonic experiences affects reinforcement learning has not yet been directly investigated in rodent models.

\subsubsection{Effects of ovarian hormones on outcome valuation and learning:} Evidence from humans

Only two studies have assessed interactions between ovarian hormones and reinforcement learning in women. As shown by Reimers et al. (2014), in the late follicular phase as compared to mid-luteal phase, women learned to slow down their response in order to maximize their rewards, but no effect was observed for speeding up the response. Better behavioral performance in the task during the follicular phase was associated with increased activation in the inferior frontal junction and rostral cingulate. As shown by preliminary results in Jakob et al. (2018), learning of active avoidance was increasingly disturbed from early to late follicular phase in women who supposedly have lower dopaminergic neurotransmission in the striatum as indicated by the presence of 9-repeat allele in their DAT1-genotype, but their reward sensitivity remained unchanged.

Similar to rodent studies, estradiol may also modulate the hedonic experience of rewards and could impact reinforcement learning rates in humans. Hummel et al. (1991) demonstrated that hedonic ratings of the chemosignal androstenone were higher at ovulation in healthy naturally cycling women relative to the rest of the menstrual cycle. During the late luteal phase women without premenstrual symptoms reported less amusement in response to emotional visual stimuli than in the midfollicular phase and had a decrease in putamen-VMPFC and putamenDMPFC functional connectivity (Dan et al., 2019). When it comes to choosing between pleasurable foods, like desserts, women preferred more variety in hedonic foods but not in non-hedonic food category during the late follicular phase in comparison to other menstrual cycle phases (Faraji-Rad et al., 2013). However, Tucci et al. (2010) did not find modulatory effects of menstrual cycle phase on hedonic ratings of hedonic foods.

The findings of Reimers et al. (2014) are consistent with the positive effect of estradiol in behavioral control discussed in Section 2.3.3. However, Jakob et al. (2018) results indicate estradiol-related disturbances in the coding of the negative RPE signal during avoidance learning particularly in women whose striatal dopamine levels are already low. A similar effect was discussed with high estradiol dose in rodent models, making it likely that by facilitating the dopaminergic neurotransmission in the limbic areas increased estradiol interferes with a suppression of the tonic dopamine signal required for coding a negative RPE. An inverted U-shape relationship between estradiol and behavioral control could be suggested (Jakob et al., 2018). Finally, increase in hedonic experience with higher estradiol might be related to positive effects of estradiol on the dopaminergic positive RPE signal and thus promote reinforcement learning.

\section{Effects of ovarian hormones in impaired decision-making in humans}

Aberrant decision-making is a core feature of several mental disorders such as substance use disorder and major depression (Wittchen et al., 2011). A profound understanding of the underlying psychological and neurobiological mechanisms of these impairments is needed to develop theory-based prevention and treatment strategies. Depending on which component is affected, dysfunctions in brain networks underlying aberrant decision-making may result in distinct patterns of cognitive, affective, and motivational phenomena in mental disorders, which open distinct avenues for prevention and specialized treatment (Goschke, 2014).

In the following, we review the modulatory effects of ovarian hormones on impaired decision-making in substance use disorder and major unipolar depression. While the decision-making impairments in substance use disorder mainly involve modulated dopaminergic signaling in the brain (Volkow et al., 2004), aberrant decision-making may be traced back to impaired serotonergic neurotransmission in depression (Dell'Osso et al., 2016). Moreover, we chose these two mental disorders as examples with prominent sexual dimorphisms both in prevalence and course, which plead for ovarian hormone related modulations of underlying psychological and neurobiological mechanisms. 


\subsection{Substance use disorder}

Substance use disorder is a relapsing neuropsychiatric illness, characterized by loss of control over drug intake. This maladaptive decision-making behavior indicates a dysregulating of the brain reward circuitry. Consummation of drugs of abuse or exposure to drug conditioned stimuli activates the mesolimbic dopamine pathway via VTA dopamine release into the NAcc (Owesson-White et al., 2009; Phillips et al., 2003; Pierce and Kumaresan, 2006). Long-term functional changes within this pathway result from chronic drug intake, i.e. from chronically enhanced activation of the mesolimbic dopamine transmission. Consequently, a sensitized increase in dopamine neurotransmission may cause morphological and functional changes in the mesolimbic reward circuitry (Hedges et al., 2010), which in turn leads to hypersensitivity to drug-associated stimuli (Di Chiara et al., 1999; Everitt and Wolf, 2002; Nestler, 2002a,b). These permanent neuroadaptations in the mesolimbic dopamine system contribute to the longterm behavioral and psychological changes observed in substance use disorder (for review see Guttman et al., 2018).

Although substance use disorders are two times more prevalent in men than in women (Grant et al., 2016), women show more severe illness progression and poorer treatment outcomes (for review see, Becker, 2016). For instance, drug use escalates more quickly and shows patterns of bingeing more often in women relative to men (Becker and $\mathrm{Hu}$, 2008; Lynch et al., 2002). Women with substance use disorder also exhibit exaggerated emotional withdrawal symptoms and craving (Hudson and Stamp, 2011), and have poorer outcomes for quitting and treatment compared with men (Becker and Hu, 2008; Lynch et al., 2002).

Women's heightened vulnerability to stages of substance use disorder, such as acquisition, escalation and relapse, has been extensively investigated in animal models. Female rodents self-administered the drug at a faster rate, showed enhanced bingeing patterns of drug intake, and were also more vulnerable to relapse of drug-seeking behavior compared with male rodents (for reviews see Anker and Carroll, 2011; Becker and Hu, 2008; Becker et al., 2012; Carroll and Anker, 2010). Based on the findings from rodent studies, one could speculate that women may be at higher risk for these behavioral dysregulations due to underlying neurobiological mechanisms related to ovarian hormones (Becker and Hu, 2008; Carroll and Anker, 2010). Enhanced drugseeking behavior and subjective drug-effects have been associated with higher levels of endogenous estradiol, while progesterone has been found to attenuate drug responses in animals and humans (Carroll and Anker, 2010; Evans, 2007; Evans and Foltin, 2006; Terner and de Wit, 2006; Evans et al., 2002; Sofuoglu et al., 1999). While this potential underlying mechanism has been extensively studied in animal models (e.g., in ovariectomized rodents; for review see Becker, 2016), research in humans is still scarce. In the following, we will evaluate hormonal modulation of decision-making mechanisms in substance use disorder with a focus on human literature.

\subsubsection{Prediction cues: Hormonal modulation of drug-associated cues and craving}

Context has a major impact on decision-making and can lead to violations of rational economic models, in which preferences change, for instance, according to the availability of other options (Tversky and Kahneman, 1989). Contextual cues of the immediate environment can have considerable effects on drug-related choices (Chase et al., 2011; Perry et al., 2014; Redish, 2004). These conditioned stimuli can enhance drug-seeking behavior (Everitt and Robbins, 2005), i.e. craving, that increases the subjective value of drug-related choices compared with alternative choices. On a neural level, drug-related cues lead to enhanced activity in meso-cortico-limbic regions (medial OFC, ventral striatum/ventral pallidum, hippocampus, amygdala, and insula) compared with neutral cues (Bonson et al., 2002; Volkow et al., 2006; Wilson et al., 2004), and in particular insula activity correlates with cue-induced craving in female and male drug users (Brody et al., 2007; Kilts et al., 2004; Sell et al., 1999).

Women show different reactions to external drug-associated cues than men (Robbins et al., 1999; Elman et al., 2001). For instance, smoking cues led to higher cue-induced craving and enhanced the hedonic and reinforcing value of smoking in women compared with men (Perkins et al., 2001; Field and Duka, 2004). On a neural level, women showed higher medial OFC activation and lower bilateral hippocampal/amygdala activation to smoking cues compared with non-smoking cues than men (Wetherill et al., 2013). On a behavioral level, women had higher craving ratings in the follicular phase compared with their luteal phase (Mello, 2010). Similarly, Franklin et al. (2015) observed that smoking-satiated women showed greater activity in the medial $\mathrm{OFC}$ and stronger craving to appetitive smoking cues in the follicular phase compared with women in the luteal phase. However, menstrual cycle phase was not hormonally verified, and authors only relied on self-report.

\subsubsection{Decision choice and outcome: Hormonal modulation of subjective responses to drugs}

Internal signals like autonomic and affective processes can influence our choices and thus our decision-making. Autonomic processes, such as increased heart rate as a proxy for arousal, alter cognitive processes and produce interoceptive signals, which contribute to affective states and decision-making (Critchley et al., 2013). The integration of these internal autonomic and affective processes is thus crucial for adaptive decision-making and has been shown to be impaired in substance use disorder (Goldstein et al., 2009). Physiological responses to affective signals are integrated with cognitive information through the insula, ACC, amygdala, and the somatosensory cortex (Medford and Critchley, 2010), all relying on activity of the VMPFC (Bechara et al., 1994). Especially the insula is involved in the influence of autonomic functions on cognition (Singer et al., 2009). Insula-dependent systems are supposed to integrate experience and recall of pleasure from interoceptive drug effects into the decision-making process (Naqvi and Bechara, 2010).

It has been shown that men had higher subjective responses to stimulants than women, but only when women were tested in their luteal phase; subjective responses were almost identical between men and women tested in their follicular phase (for review see Evans, 2007). Thus, in women, subjective responses to stimulants were greater in the follicular phase than in the luteal phase (e.g., Justice and de Wit, 1999; White et al., 2002; for review see Terner and de Wit, 2006). For instance, the subjective evaluation of 'liking' a low dose of amphetamine, i.e. the psychological response, was increased during the late follicular phase when endogenous estradiol levels were high and unopposed by progesterone (Justice and De Wit, 2000). Similarly, women reported more pleasurable responses to amphetamine together with a stronger desire for more drugs when an estradiol patch was applied during the early follicular phase (Justice and De Wit, 2000). In contrast, psychological responses to cocaine or amphetamine were blunted during the luteal phase, when progesterone is also elevated (Evans, 2007). In sum, responses of 'liking' the drug, 'wanting' more of the drug, feeling 'high', or craving were lower during the luteal phase (Justice and de Wit, 1999; Sinha et al., 2007; Sofuoglu et al., 1999; White et al., 2002). On the physiological level, women showed attenuated heart rate and blood pressure to cocaine or cocaine-related cues in the luteal phase relative to the follicular phase (Sinha et al., 2007; Sofuoglu et al., 1999). However, in contrast to results from rodent studies, the above reported human studies provide only little evidence that estradiol is responsible for enhanced subjective responses to stimulants in humans. Rather, progesterone seems to be of particular interest, based on the compelling evidence that progesterone may be effective in reducing self-administration of stimulants and relapse in female rats (Evans and Foltin, 2010; Hudson and Stamp, 2011). In humans, this has been more difficult to demonstrate and further studies are warranted to highlight 
progesterone's clinical utility for reducing relapse in women (Reed et al., 2011).

\subsubsection{Action selection and learning: Hormonal modulation of relapse and treatment}

Relapse is probably the most challenging feature of substance use disorder, with more than two thirds of patients relapsing within weeks to months after initiating treatment and more than $85 \%$ within one year (for review see Sinha, 2011). The exact mechanisms why such longlasting urges to use drugs exist are still not fully understood. Yet, the persistent nature of drug-craving and the resulting adverse decisionmaking to reinitiate drug-use indicate that substance use disorder is characterized by long-term changes in brain function, especially those related to outcome valuation and learning mechanisms.

Women and men are differently affected by relapse, e.g. women are less likely to achieve long-term abstinence (Smith et al., 2016) and have greater difficulty quitting than men (McKee et al., 2016; Wetter et al., 1999). This sex difference in relapse vulnerability is most commonly reported for cigarette smoking (Smith et al., 2016). Interestingly, women showed improved smoking cessation outcomes when they attempted to quit smoking in the luteal phase, i.e. when progesterone is high, compared to the follicular phase, i.e. when progesterone is low (Allen et al., 2008), in line with rodent data where progesterone was effective in reducing self-administration of stimulants and relapse (Evans and Foltin, 2010; Hudson and Stamp, 2011).

A recent double-blind placebo-controlled randomized trial investigated the effects of long-term exogenous progesterone administration (200 mg twice daily for 12 weeks) on smoking cessation outcomes and smoking-related symptomatology (withdrawal, craving, mood, and stress) in women and men (Tosun et al., 2019). Compared with women in the placebo group, women receiving progesterone had three times higher odds of abstinence at week 4 and about six more abstinent days before they relapsed. However, there was no effect of progesterone treatment on cessation outcomes in men at any time point. This finding complements studies which reported that 8-12 weeks of progesterone administration helps preventing smoking relapse in postpartum women (Allen et al., 2016; Forray et al., 2017). Yet, the causal mechanisms and neurobiological underpinnings of this promising avenue of hormone administration for treatment of substance use disorder, especially in women, are still lacking.

\subsubsection{Summary}

The course of substance use disorder differs between men and women, with women showing different risk and susceptibility rates to certain phases of addiction. Evidence from rodent and human studies suggest that these differences arise due to ovarian hormone effects on underlying neurobiological mechanisms of decision-making (Becker and Hu, 2008; Carroll and Anker, 2010).

In summary, women have higher ratings of craving in the follicular phase compared with the luteal phase, both on a behavioral and a neural level. Similarly, women show greater subjective responses to drug stimuli, both on a psychological and physiological level, in the follicular phase compared with the luteal phase. Together with findings from animal and human studies as reviewed above (please see 2.3.2 and 2.3.3), it has been suggested that it is rather the attenuating effect of progesterone on subjective drug responses in the luteal phase than the elevating effect of estradiol on subjective drug responses in the follicular phase that accounts for this difference. This hypothesis has already been successfully translated into new treatment developments: both acute and long-term progesterone administration leads to improved smoking and stimulant cessation outcomes in women.

However, clinical research in women is still scarce and does not always complement preclinical findings. Moreover, precise designations of menstrual cycle phases are often lacking as well as biochemical verification of hormonal levels (see also Table S1). On a more general level, so far it is not well understood how ovarian hormones impact decision-making in substance use disorder in women. Understanding the neurobiological mechanisms and neurotransmitter systems involved in generating the proposed effects of ovarian hormones is an important step for developing specifically tailored treatment trajectories for women, which can then be tested in rigorous randomized controlled trials, e.g. scheduling a quit date when subjective drug responses are less intense and developing hormone-targeted treatments.

\subsection{Depression}

Unipolar depression has been consistently associated with monoaminergic imbalance, most prominently with altered serotonin function (Deakin, 1991). Low levels of serotonin have been associated with behavioral inhibition, a hypothesis that is supported by empirical data showing that depleting central serotonin reduced behavioral activation (for review see Cools et al., 2008). Next to depressed mood, anhedonia is a core feature of depression and describes reduced interest or pleasure in normally rewarding activities (Eshel and Roiser, 2010). This negative bias in reward processing, together with aberrations in striatal connectivity have also been reported to be predictive of depression onset (Morgan et al., 2013; Stringaris et al., 2015; Pan et al., 2017). A recent meta-analysis found blunted striatal activity during reward feedback in patients with depression compared with healthy volunteers, most consistently shown in the caudate, but also in putamen and globus pallidus (Keren et al., 2018). Especially the robust findings for the caudate have been interpreted as evidence for reduced reinforcement of actions in depressed individuals.

Women experience unipolar depression twice as often as men in their lives, starting with puberty (Kuehner, 2017). However, to date it is not fully understood whether this female preponderance is related to ovarian hormone dynamics. Hormonal transition phases, e.g. puberty, postpartum or menopause, are defined by larger alterations in endogenous hormone levels in women; these phases have been associated with considerable mood changes and elevated risk for depression onset (Freeman et al., 2014; Munk-Olsen et al., 2006; Zsido et al., 2017; Lewis et al., 2019).

Rodent models of postpartum depression provide a first link between ovarian hormones and impaired decision-making in depression: female rodents showed a reduced preference for sucrose following ovarian hormone withdrawal, which could be alleviated with estradiol treatment (Galea et al., 2001; Green et al., 2009; for review see Brummelte and Galea, 2016). Similarly, in a rodent model of premenstrual dysphoria, abrupt withdrawal from physiological doses of progesterone led to depressive behavior, including anhedonia in the sucrose preference test (Li et al., 2012). However, if and how transitions in ovarian hormone levels impact decision-making in the human brain is still poorly understood. In the following, we will outline hormonal modulation of decision-making mechanisms, which could underlie variation in mood and thus eventually contribute to depression risk.

\subsubsection{Valuation: Hormonal modulation of response to positive stimuli}

A blunted hedonic response to rewards can underlie a negative bias in reward processing which has been shown in patients with unipolar depression (Eshel and Roiser, 2010). Macoveanu et al. (2016) used a gonadotropin-releasing hormone agonist (GnRHa) administration in a double-blind, placebo-controlled design to investigate the brain response to monetary rewards in healthy premenopausal women. GnRHa administration manipulates endogenous ovarian hormone milieu, by first increasing hormone levels which is then followed by a rapid decline. Following this acute decline in ovarian hormone levels, women had increased depression symptoms and reduced amygdala responses to monetary rewards. The acute change in ovarian hormone levels may impact the cortico-limbic top-down control of emotional valuation of reward encoded by the amygdala (Murray, 2007). This fits well with the finding that depressed patients show decreased attentional bias to positive stimuli, with decreased responses in amygdala and ventral 
striatum (Leppänen, 2006; Victor et al., 2010; Stuhrmann et al., 2013). Furthermore, the decreased response of the ventral striatum and amygdala to positive stimuli has been associated with anhedonia, and not depression scores per se (Keedwell et al., 2005).

\subsubsection{Action selection and execution: Hormonal modulation of behavioral inhibition}

Using acute tryptophan depletion to mimic the impairment of the serotonergic neurotransmission in depression, Helmbold et al. (2015) investigated serotonergic modulation of behavioral inhibition in a ' $\mathrm{Go}$ / No-Go' task with reward and punishment conditions (Crockett et al., 2009 ) in healthy women during the early follicular phase. Neural activation during 'No-Go' trials in the punishment condition was positively correlated with the magnitude of serotonin depletion in the right OFC, right subgenual ACC, left ventral ACC, and left inferior temporal area. However, this study did not include male participants and it is thus not possible to draw inferences if the observed results are female specific. Moreover, although this study controlled for menstrual cycle phase by measuring all women during the early follicular phase when ovarian hormones are low, a hormone-specific interpretation of the obtained results is limited.

Bannbers et al. (2012) investigated women diagnosed with premenstrual dysphoric disorder (PMDD) and healthy control women twice, once during the mid-follicular phase and once during the late luteal phase using a lexical 'Go/No-Go' task. Women with PMDD experience symptoms equivalent to a major depressive episode during the premenstrual, i.e. late luteal phase (Epperson et al., 2012). It is hypothesized that women with PMDD are particularly susceptible to subtle hormonal changes across the menstrual cycle (Bäckström et al., 2003). Bannbers et al. (2012) reported decreased activation in the midfollicular phase and increased activation in the late luteal phase in PMDD patients compared with controls in the left insula during response inhibition. Additionally, the within-group comparison revealed enhanced insula activity during the late luteal vs. mid-follicular phase in PMDD. Moreover, PMDD women showed a general decrease in brain activation in parietal regions and right caudate body during response inhibition compared with controls, independent of menstrual cycle phase. While the study by Bannbers et al. (2012) did not find any differences in behavioral performance, Yen et al. (2014) reported deficits in response inhibition performance in a numerical 'Go/No-Go' task in PMDD women compared to healthy controls. Specifically, women with PMDD had more commission errors in 'Go' trials in the premenstrual phase compared with healthy controls, which may reflect impaired sustained attention in PMDD in this phase. Most importantly, this effect was observed only in PMDD women with the G allele of the serotonin 1A receptor polymorphism (HTR1A; rs6295). Moreover, changes in estradiol level from the follicular phase to the premenstrual phase were negatively associated with performance in the 'Go/No-Go' task. Thus, the results from studies investigating women with PMDD can not only be interpreted in terms of activational changes induced by ovarian hormones, but also suggest an association with altered serotonergic neurotransmission across the menstrual cycle in response inhibition. Yet, this suggested mechanism needs to be further tested.

\subsubsection{Outcome valuation and learning: Hormonal modulation of feedback and goal-directed behavior}

Mulligan et al. (2018) investigated healthy women's event-relatedpotentials (ERPs) in response to monetary reward and loss in the midfollicular and the mid-luteal phase (within-subject design). Additionally, women filled out a depression symptom inventory at both time-points, indicating no significant differences in self-reported symptoms between cycle phases. However, participants with high overall depression scores showed a reduced ERP to rewards in the midluteal phase as compared to the mid-follicular phase, whereas participants with low depression scores showed a similar ERP to rewards in both cycle phases. Depressive symptoms were not associated with ERPs to monetary loss. Reduced ERPs to rewards have previously been found in individuals at risk for depression (Bress et al., 2013; Nelson et al., 2016; Proudfit, 2015). More specifically, ERPs to rewards have been suggested to reflect a reward prediction error signal in the ACC, which alleviates adaptive goal-directed behavior and contributes to learning (Holroyd and Coles, 2002; Holroyd et al., 2008; Sambrook and Goslin, 2015; Walsh and Anderson, 2012). Based on this, it can be suggested that depressive symptoms may moderate the hormonal impact on one's ability to engage in adaptive goal-directed behavior in response to reward feedback.

\subsubsection{Summary}

Acute changes in ovarian hormone levels may increase the vulnerability for depression in women by modulating their response to rewarding stimuli. To the best of our knowledge, there are only few human studies directly investigating this association on a neural level.

Following an acute pharmacologically induced decline in ovarian hormone levels, i.e. mimicking the postpartum period or menopausal declines, women had increased depression symptoms and reduced amygdala responses to monetary rewards. This may reflect reduced affective processing of positive, rewarding experiences following the decline of ovarian hormones, in line with the decreased attentional bias to positive stimuli in depression. Menstrual cycle phase dependent differences in response inhibition in women with PMDD - both within the PMDD group and in between-group comparisons with healthy controls - provide another indication for hormonal modulation of decision-making in depression. Women with PMDD had deficits in response inhibition performance and increased activation in areas associated with cognitive and affective processing in the luteal phase; contrary to findings from health women, who mainly showed stronger activation during the mid to late follicular phase (as compared to the luteal phase). With a stronger focus on depressive symptomatology, it has been shown that women had menstrual cycle phase related differences in brain activation in response inhibition tasks, following pharmacologically induced reduced serotonergic neurotransmission. Moreover, depressive symptoms moderated the hormonal impact on adaptive goal-directed behavior, with reduced responses to reward feedback in the luteal phase compared with the follicular phase.

In summary, there is a clear paucity of studies investigating ovarian hormone related influences in women on impaired decision-making in depression. To date, we have no conclusive understanding of the neurobiological mechanisms, which may underlie these aberrations. We are in need of studies which pharmacologically alter both serotonin and ovarian hormone levels in order to deduct a mechanistic understanding. This is a critical gap to develop specifically tailored prevention and hormone-targeted treatment trajectories for women suffering from depression or are at risk for depression.

\section{Conclusions and future perspectives}

Variation of ovarian hormones over the menstrual cycle have an impact on decision-making on a behavioral as well as neural level. However, what these modulatory effects are and how they influence the changes in different elements of decision-making, is still largely understudied. In this review we were able to suggest some hypotheses on what the possible roles of estradiol and progesterone in modulating decision-making may be but more attention and model-based approaches to this research topic are necessary. Most of the discussed studies do not provide consistent results and replications of tentative findings are mostly missing.

When studying value-based decision-making, it is important to recognize its complexity. As Rangel et al. (2008) point out, decisionmaking can be divided into distinct components. Each of these components could be considered as a separate neurobiological process and may be differently modulated by internal and external factors. While neurocomputational methods are increasingly used to understand the 
underlying neurobiological mechanisms of these decision-making elements and their interactions, the distinction between the elements is not yet clearly implemented in the experimental paradigms assessing the modulatory effects of ovarian hormones in decision-making. In this review, we attempted to fit different research paradigms into this distinction of decision-making elements to better understand the roles of ovarian hormones and their interaction with neurotransmitter systems when it comes to decision-making. We are not, however, claiming that this is the only way to differentiate between decision-making elements and their respective experimental paradigms. We do nevertheless hope that future studies will recognize the benefits of breaking down decision-making into smaller components as it allows the researchers to target different computational signals, neurotransmitter systems as well as behavioral aspects of decision-making.

Moreover, we found that the decision-making components are differently modulated by varying ovarian hormones. However, not in every aspect of decision-making animal and human findings were consistent. While rising estradiol increased the dopaminergic signaling in the limbic areas and thus facilitated attention to reward cues in rodents, in humans an opposite effect was found. More consistently, estradiol (i) played a positive role in effort expenditure and cognitive control during action selection, most likely by interacting with neurotransmitter systems in higher cortical areas, especially prefrontal areas; (ii) augmented the hedonic qualities of the reward; and thus (iii) facilitated approach behavior; but also (iv) impeded avoidance learning. However, discrepancies between animal and human findings should be considered in light of a number of methodological differences. In animals, hormone levels are often manipulated via gonadectomy and exogenous hormone administration, while natural hormone variations in humans are mainly evaluated by comparing different stages of the menstrual cycle with each other. Following gonadectomy, some animal studies use different hormone replacement regimes, including supraphysiological doses, rendering a direct comparison to findings in humans difficult (Bowen et al., 2012; Wallin et al., 2015). Furthermore, most animal studies rely on rodent models, which are, although wellestablished, inadequate to fully capture the hormonal variations seen across the human menstrual cycle (see Fig. 2). Non-human primates more closely resemble the human menstrual cycle, however, the long lifespan, high expenses, and substantial barriers to access non-human primates (Brinton, 2012) as well as ethical considerations make it hard for laboratories to study these animals as translational models. Another major methodological difference is the tight experimental control over the environment in animals but not humans, likely impacting behavioral choices and actions.

Relative to estradiol, a lot less has been found on the role of progesterone in decision-making, both in rodents and humans. Yet the available findings indicate that progesterone acts beyond by attenuating the effects of estradiol. More research is necessary to understand how progesterone is interacting with neurotransmitter systems and other sex hormones in decision-making. Furthermore, it is worthwhile noting, that most animal and human studies assume classical hormonal variations across the estrous and menstrual cycle, of on average $96 \mathrm{~h}$ and 28 days, respectively (see Fig. 2). However, cycle length and the amplitude of cyclical changes in hormone levels largely vary within and between individuals (Schank, 2000). This high amount of heterogeneity may lead to individual differences in decision-making between cycles, and may contribute to inconsistencies in results across studies. Future studies may employ a repeated measures within-individual design across more than one estrous/menstrual cycle to study potential variations in decision-making strategies on an individual level.

Another prospective line of future research could target the role of ovarian hormones in modulating decision-making aspects which depend on higher cortical areas, especially prefrontal cortex and cingulate cortex. These brain areas are involved in processing more than one function in decision-making, therefore, by applying a model-based approach and differentiating between the more intricate decision-making elements, the influence of ovarian hormones could be better characterized.

The valence dimension has also been overlooked when it comes to the effects of ovarian hormones in decision-making. Although we have made effort to cover the evidence on the interaction during positively and negatively valenced decision-making, the number of studies using rewards as stimuli are far greater than the studies using punishment. Affective bias formation and variation in valence perception could be modulated by ovarian hormones, therefore, future studies should address both ends of the valence spectrum. Neuroimaging studies could profit from closer investigations of the amygdala-OFC and amygdalastriatum connections in relation to valence.

Another limitation of discussing the effects of ovarian hormones on decision-making is that they do not function in isolation from the rest of the endocrine system. Other hormones, like testosterone and cortisol, have been indicated as modulators of decision-making processes. A combined approach, testing effects of ovarian hormones and the presence of testosterone in women, could help to further understand their interaction and contribution in decision-making. Contrary to biological modulators of decision-making, research on influential psychosocial factors is still sparse. Emerging evidence suggests that environmental stressors such as early adverse life events (e.g. childhood trauma) in combination with genetic factors might influence decision-making abilities and the risk for mood disorders (Guillaume et al., 2013; Stoltenberg et al., 2011). However, whether environmental factors may alter observed hormone-neurotransmitter interaction effects in decision-making is largely unknown, and represents a fascinating avenue for future research. Understanding the biopsychosocial architecture of decision-making will have broad societal implications.

In this review, we focused on substance use disorders and unipolar depression to illustrate how ovarian hormones interact with impairments of separate decision-making aspects. Unfortunately, there is a clear lack of studies which systematically investigate hormone-related decision-making deficits in women with these disorders. This is a critical gap in research as this knowledge is crucial to understand individual differences in prevalence, course, and treatment response in psychiatric pathologies. Integration of results from healthy populations and clinical samples is challenging due to several methodological limitations: i) although similar tasks have been used (e.g. Go/No-Go) there are several versions available (numerical, lexical, verbal, monetary, etc.) which hinder direct comparisons, and ii) the phases of the menstrual cycle when healthy individuals vs. patients were measured vary. So far, no study systematically investigated the effects of the different menstrual cycle phases or hormone levels (e.g. using hormone administration such as GnRHa) in healthy women and in female patients suffering from substance use disorder or major depression, using the same methods (e.g. menstrual cycle staging, hormone assessment, tasks). Also, to our knowledge, no study has investigated the same decision-making processes in different female patient groups while considering ovarian hormone levels. Trying to combine what has been reported in both disorders, it seems that higher ovarian hormone levels increase craving and the subjective response to stimulants in substance use disorder, while affecting attentional biases to positive stimuli in depression which has been particularly associated with anhedonia. During the late luteal phase, when estradiol and progesterone are low, reduced sustained attention and higher insula activation have been reported in women suffering from PMDD. Interestingly, during the luteal phase, women also reported blunted responses to stimulants compared to the follicular phase. Thus, while mood symptoms may be potentiated by the decline of ovarian hormones, enhanced craving and risk for relapse have been reported during phases when ovarian hormones are high.

Currently several issues remain unsolved including (i) the underlying neurobiological mechanisms and receptor systems involved in modulating the effects of ovarian hormones on decision-making in mental disorders are not fully understood to date; (ii) clinical research 
in women is still scarce and does not always complement findings from rodent studies; (iii) precise designation of menstrual cycle phases and hormonal verifications in general are often lacking; (iv) research specifically investigating hormonal transition periods across the female lifespan, i.e. pregnancy, postpartum, or menopause, is still scarce, in both healthy and clinical populations.

We encourage future studies to tackle these issues and provide by separating specific elements of decision-making a general framework to systematically investigate decision-making deficits in women. Our approach is in line with current research initiatives like the Research Domain Criteria (RDoC; Cuthbert and Insel, 2013; Insel, 2014) framework, which reflects the need for psychiatry to move beyond the mere observation of symptoms and to integrate many levels of psychological and biological systems in order to understand basic dimensions of human functioning. Up to now, the impact of ovarian hormones and thus the systematic investigation of hormonal alteration and transition periods has not been included in the RDoC domains. While research in substance use disorders already provides first promising avenues from systematic investigations of decision-making deficits in women, e.g. scheduling a quit date during the menstrual cycle when subjective drug responses are less intense and developing hormone-targeted treatments, research in depression-related decision-making deficits in women is still in its infancy. Acknowledging the possible effects of the menstrual cycle is an important step for developing tailored preventive strategies and treatment regimens for women in general, and specifically for phases with severe changes in ovarian hormone levels in women, such as pregnancy, postpartum, or menopause.

\section{Funding}

CAL and BD were supported by the German Research Foundation, DFG (DE2319/2-4, DE2319/6-1, DE2319/9-1). CB was supported by Research Council of Norway (\#250358).

\section{Declaration of Competing Interest}

The authors declare that they have no known competing financial interests or personal relationships that could have appeared to influence the work reported in this paper.

\section{Appendix A. Supplementary material}

Supplementary data to this article can be found online at https:// doi.org/10.1016/j.yfrne.2020.100873.

\section{References}

Ainslie, G., 1975. Specious reward: a behavioral theory of impulsiveness and impulse control. Psychol. Bull. 82 (4), 463-496. https://doi.org/10.1037/h0076860.

Alexander, A., Irving, A.J., Harvey, J., 2017. Emerging roles for the novel estrogen-sensing receptor GPER1 in the CNS. Neuropharmacology 113 (Pt B), 652-660. https:// doi.org/10.1016/j.neuropharm.2016.07.003.

Allen, S.S., Allen, A.M., Lunos, S., Tosun, N., 2016. Progesterone and postpartum smoking relapse: a pilot double-blind placebo-controlled randomized trial. NICTOB 18 (11), 2145-2153.

Allen, S.S., Bade, T., Center, B., Finstad, D., Hatsukami, D., 2008. Menstrual phase effects on smoking relapse. Addiction 103 (5), 809-821. https://doi.org/10.1111/j.13600443.2008.02146.x.

Almey, A., Arena, L., Oliel, J., Shams, W.M., Hafez, N., Mancinelli, C., Henning, L., Tsanev, A., Brake, W.G., 2017. Interactions between estradiol and haloperidol on perseveration and reversal learning in amphetamine-sensitized female rats. Horm. Behav. 89, 113-120.

Almey, A., Milner, T.A., Brake, W.G., 2015. Estrogen receptors in the central nervous system and their implication for dopamine-dependent cognition in females. Horm. Behav. 74, 125-138.

Alonso-Alonso, M., Ziemke, F., Magkos, F., Barrios, F.A., Brinkoetter, M., Boyd, I., RifkinGraboi, A., Yannakoulia, M., Rojas, R., Pascual-Leone, A., Mantzoros, C.S., 2011. Brain responses to food images during the early and late follicular phase of the menstrual cycle in healthy young women: relation to fasting and feeding. Am. J. Clin. Nutr. 94 (2), 377-384. https://doi.org/10.3945/ajcn.110.010736.

Amemori, K.-I., Graybiel, A.M., 2012. Localized microstimulation of primate pregenual cingulate cortex induces negative decision-making. Nat. Neurosci. 15 (5), 776-785. Amin, Z., Epperson, C.N., Constable, R.T., Canli, T., 2006. Effects of estrogen variation on neural correlates of emotional response inhibition. NeuroImage 32 (1), 457-464.

Anderson, L.C., Petrovich, G.D., 2015. Renewal of conditioned responding to food cues in rats: sex differences and relevance of estradiol. Physiol. Behav. 151, 338-344.

Anker, J.J., Carroll, M.E., 2011. Females are more vulnerable to drug abuse than males: evidence from preclinical studies and the role of ovarian hormones. Curr. Top. Behav. Neurosci. 8, 73-96. https://doi.org/10.1007/7854_2010_93.

Arad, M., Weiner, I., 2012. Abnormally rapid reversal learning and reduced response to antipsychotic drugs following ovariectomy in female rats. Psychoneuroendocrinology 37 (2), 200-212.

Auger, A.P., Meredith, J.M., Snyder, G.L., Blaustein, J.D., 2001. Oestradiol increases phosphorylation of a dopamine- and cyclic AMP-regulated phosphoprotein (DARPP32) in female rat brain. J. Neuroendocrinol. 13 (9), 761-768. https://doi.org/10. 1046/j.1365-2826.2001.00777.x.

Ayano, G., 2016. Dopamine: receptors, functions, synthesis, pathways, locations and mental disorders: review of literatures. J. Ment. Disord. Treat. 2 (2), 120. https://doi. org/10.4172/2471-271x.1000120.

Azcoitia, I., Yague, J.G., Garcia-Segura, L.M., 2011. Estradiol synthesis within the human brain. Neuroscience 191, 139-147.

Backstrom, T., Andersson, A., Andree, L., Birzniece, V., Bixo, M., Bjorn, I., Haage, D., Isaksson, M., Johansson, I.M., Lindblad, C., Lundgren, P., Nyberg, S., Odmark, I.S., Stromberg, J., Sundstrom-Poromaa, I., Turkmen, S., Wahlstrom, G., Wang, M., Wihlback, A.C., Zhu, D., Zingmark, E., 2003. Pathogenesis in menstrual cycle-linked CNS disorders. Ann. N Y Acad. Sci. 1007, 42-53. https://doi.org/10.1196/annals. 1286.005 .

Banis, S., Lorist, M.M., 2017. The combined effects of menstrual cycle phase and acute stress on reward-related processing. Biol. Psychol. 125, 130-145.

Bannbers, E., Gingnell, M., Engman, J., Morell, A., Comasco, E., Kask, K., Garavan, H., Wikström, J., Sundström Poromaa, I., 2012. The effect of premenstrual dysphoric disorder and menstrual cycle phase on brain activity during response inhibition. J. Affect. Disord. 142 (1-3), 347-350.

Barth, C., Villringer, A., Sacher, J., 2015. Sex hormones affect neurotransmitters and shape the adult female brain during hormonal transition periods. Front. Neurosci. 9, 37. https://doi.org/10.3389/fnins.2015.00037.

Bartra, O., McGuire, J.T., Kable, J.W., 2013. The valuation system: a coordinate-based meta-analysis of BOLD fMRI experiments examining neural correlates of subjective value. NeuroImage 76, 412-427.

Basten, U., Biele, G., Heekeren, H.R., Fiebach, C.J., 2010. How the brain integrates costs and benefits during decision making. Proc. Natl. Acad. Sci. 107 (50), 21767-21772.

Bayer, J., Bandurski, P., Sommer, T., 2013. Differential modulation of activity related to the anticipation of monetary gains and losses across the menstrual cycle. Eur. J. Neurosci. 38 (10), 3519-3526.

Bazzett, T.J., Becker, J.B., 1994. Sex differences in the rapid and acute effects of estrogen on striatal D2 dopamine receptor binding. Brain Res. 637 (1-2), 163-172.

Bechara, A., Damasio, A.R., Damasio, H., Anderson, S.W., 1994. Insensitivity to future consequences following damage to human prefrontal cortex. Cognition 50 (1-3), $7-15$.

Becker, J.B., 1990a. Direct effect of 17B-estradiol on striatum: sex differences in dopamine release. Synapse 5 (2), 157-164. https://doi.org/10.1002/syn.890050211.

Becker, J.B., 1990b. Estrogen rapidly potentiates amphetamine-induced striatal dopamine release and rotational behavior during microdialysis. Neurosci. Lett. 118 (2), $169-171$.

Becker, J.B., 1999. Gender differences in dopaminergic function in striatum and nucleus accumbens. Pharmacol. Biochem. Behav, 64 (4), 803-812.

Becker, J.B., 2016. Sex differences in addiction. Dialogues Clin. Neurosci. 18 (4), 395-402.

Becker, J.B., Chartoff, E., 2019. Sex differences in neural mechanisms mediating reward and addiction. Neuropsychopharmacol 44 (1), 166-183.

Becker, J.B., Hu, M., 2008. Sex differences in drug abuse. Front. Neuroendocrinol. 29 (1), $36-47$.

Becker, J.B., Perry, A.N., Westenbroek, C., 2012. Sex differences in the neural mechanisms mediating addiction: a new synthesis and hypothesis. Biol. Sex Dif. 3 (1), 14. https://doi.org/10.1186/2042-6410-3-14.

Berridge, K.C., Robinson, T.E., 1998. What is the role of dopamine in reward: hedonic impact, reward learning, or incentive salience? Brain Res. Rev. 28 (3), 309-369.

Bethea, C.L., 1993. Colocalization of progestin receptors with serotonin in raphe neurons of macaque. Neuroendocrinology 57 (1), 1-6. https://doi.org/10.1159/000126334.

Bless, E.P., McGinnis, K.A., Mitchell, A.L., Hartwell, A., Mitchell, J.B., 1997. The effects of gonadal steroids on brain stimulation reward in female rats. Behav. Brain Res. 82 (2), 235-244.

Bonenberger, M., Groschwitz, R.C., Kumpfmueller, D., Groen, G., Plener, P.L., Abler, B., 2013. It's all about money: oral contraception alters neural reward processing. NeuroReport 24 (17), 951-955.

Bonson, K.R., Grant, S.J., Contoreggi, C.S., Links, J.M., Metcalfe, J., Weyl, H.L., Kurian, V., Ernst, M., London, E.D., 2002. Neural systems and cue-induced cocaine craving. Neuropsychopharmacology 26 (3), 376-386. https://doi.org/10.1016/S0893-133X (01)00371-2.

Borrow, A.P., Cameron, N.M., 2014. Estrogenic mediation of serotonergic and neurotrophic systems: implications for female mood disorders. Prog. Neuropsychopharmacol. Biol. Psychiatry 54, 13-25.

Boureau, Y.-L., Dayan, P., 2011. Opponency revisited: competition and cooperation between dopamine and serotonin. Neuropsychopharmacol 36 (1), 74-97.

Bouret, S., Richmond, B.J., 2010. Ventromedial and orbital prefrontal neurons differentially encode internally and externally driven motivational values in monkeys. J. Neurosci. 30 (25), 8591-8601. 
Bowen, R.S., Knab, A.M., Hamilton, A.T., McCall, J.R., Moore-Harrison, T.L., Lightfoot, J.T., 2012. Effects of supraphysiological doses of sex steroids on wheel running activity in mice. J. Steroids Horm. Sci. 3 (2), 110. https://doi.org/10.4172/2157-7536. 1000110 .

Bress, J.N., Foti, D., Kotov, R., Klein, D.N., Hajcak, G., 2013. Blunted neural response to rewards prospectively predicts depression in adolescent girls: Feedback negativity predicts depression. Psychophysiol 50 (1), 74-81.

Brinton, R.D., 2012. Minireview: translational animal models of human menopause: challenges and emerging opportunities. Endocrinology 153 (8), 3571-3578. https:// doi.org/10.1210/en.2012-1340.

Brinton, R.D., Thompson, R.F., Foy, M.R., Baudry, M., Wang, JunMing, Finch, C.E. Morgan, T.E., Pike, C.J., Mack, W.J., Stanczyk, F.Z., Nilsen, J., 2008. Progesterone receptors: form and function in brain. Front. Neuroendocrinol. 29 (2), 313-339.

Brinton, R.D., Yao, J., Yin, F., Mack, W.J., Cadenas, E., 2015. Perimenopause as a neurological transition state. Nat. Rev. Endocrinol. 11 (7), 393-405.

Brody, A.L., Mandelkern, M.A., Olmstead, R.E., Jou, J., Tiongson, E., Allen, V., Scheibal, D., London, E.D., Monterosso, J.R., Tiffany, S.T., Korb, A., Gan, J.J., Cohen, M.S., 2007. Neural substrates of resisting craving during cigarette cue exposure. Biol. Psychiatry 62 (6), 642-651.

Brummelte, S., Galea, L.A.M., 2016. Postpartum depression: Etiology, treatment and consequences for maternal care. Horm. Behav. 77, 153-166.

Bull, J.R., Rowland, S.P., Scherwitzl, E.B., Scherwitzl, R., Danielsson, K.G., Harper, J., 2019. Real-world menstrual cycle characteristics of more than 600,000 menstrual cycles. NPJ Digit Med. 2 (1), 83. https://doi.org/10.1038/s41746-019-0152-7.

Byrne, K.A., Worthy, D.A., 2015. Gender differences in reward sensitivity and information processing during decision-making. J. Risk Uncertain 50 (1), 55-71.

Calipari, E.S., Juarez, B., Morel, C., Walker, D.M., Cahill, M.E., Ribeiro, E., Roman-Ortiz, C., Ramakrishnan, C., Deisseroth, K., Han, M.-H., Nestler, E.J., 2017. Dopaminergic dynamics underlying sex-specific cocaine reward. Nat. Comm. 8 (1), 13877. https:// doi.org/10.1038/ncomms13877.

Cao, Z., Liao, Q., Su, M., Huang, K., Jin, J., Cao, D., 2019. AKT and ERK dual inhibitors: the way forward? Cancer Lett. 459, 30-40.

Carroll, M.E., Anker, J.J., 2010. Sex differences and ovarian hormones in animal models of drug dependence. Horm. Behav. 58 (1), 44-56.

Cavada, C., Company, T., Tejedor, J., Cruz-Rizzolo, R.J., Reinoso-Suarez, F., 2000. The anatomical connections of the macaque monkey orbitofrontal cortex. A review. Cereb. Cortex 10 (3), 220-242. https://doi.org/10.1093/cercor/10.3.220.

Chase, H.W., Eickhoff, S.B., Laird, A.R., Hogarth, L., 2011. The Neural basis of drug stimulus processing and craving: an activation likelihood estimation meta-analysis. Biol. Psychiatry 70 (8), 785-793.

Chong, T.T.J., Apps, M., Giehl, K., Sillence, A., Grima, L.L., Husain, M., 2017. Neurocomputational mechanisms underlying subjective valuation of effort costs. PLOS Biol. 15 (2). https://doi.org/10.1371/journal.pbio.1002598.

Cohen, J.Y., Amoroso, M.W., Uchida, N., 2015. Serotonergic neurons signal reward and punishment on multiple timescales. Elife 4, e06346. https://doi.org/10.7554/eLife. 06346.

Cohen, J.Y., Haesler, S., Vong, L., Lowell, B.B., Uchida, N., 2012. Neuron-type-specific signals for reward and punishment in the ventral tegmental area. Nature 482 (7383), $85-88$.

Colzato, L.S., Hertsig, G., van den Wildenberg, W.P.M., Hommel, B., 2010. Estrogen modulates inhibitory control in healthy human females: evidence from the stopsignal paradigm. Neuroscience 167 (3), 709-715.

Colzato, L.S., Pratt, J., Hommel, B., 2012. Estrogen modulates inhibition of return in healthy human females. Neuropsychologia 50 (1), 98-103.

Cools, R., Nakamura, K., Daw, N.D., 2011. Serotonin and dopamine: unifying affective, activational, and decision functions. Neuropsychopharmacol 36 (1), 98-113.

Cools, R., Roberts, A.C., Robbins, T.W., 2008. Serotoninergic regulation of emotional and behavioural control processes. Trends Cognit. Sci. 12 (1), 31-40.

Cornil, C.A., Ball, G.F., Balthazart, J., 2006. Functional significance of the rapid regulation of brain estrogen action: where do the estrogens come from? Brain Res. 1126 (1), $2-26$.

Cornwall, A.C., Byrne, K.A., Worthy, D.A., 2018. Gender differences in preference for reward frequency versus reward magnitude in decision-making under uncertainty. Personality Individ. Differ. 135, 40-44.

Cox, J., Witten, I.B., 2019. Striatal circuits for reward learning and decision-making. Nat. Rev. Neurosci. 20 (8), 482-494.

Creutz, L.M., Kritzer, M.F., 2004. Mesostriatal and mesolimbic projections of midbrain neurons immunoreactive for estrogen receptor beta or androgen receptors in rats. $J$. Comp. Neurol. 476 (4), 348-362.

Critchley, H.D., Eccles, J., Garfinkel, S.N., 2013. Interaction between cognition, emotion, and the autonomic nervous system. Handb. Clin. Neurol. 117, 59-77. https://doi. org/10.1016/b978-0-444-53491-0.00006-7.

Crockett, M.J., Clark, L., Robbins, T.W., 2009. Reconciling the role of serotonin in behavioral inhibition and aversion: acute tryptophan depletion abolishes punishmentinduced inhibition in humans. J. Neurosci. 29 (38), 11993-11999.

Crone, E.A., Bullens, L., van der Plas, E.A.A., Kijkuit, E.J., Zelazo, P.D., 2008. Developmental changes and individual differences in risk and perspective taking in adolescence. Dev. Psychopathol. 20 (4), 1213-1229.

Croxson, P.L., Walton, M.E., O'Reilly, J.X., Behrens, T.E.J., Rushworth, M.F.S., 2009 Effort-based cost-benefit valuation and the human brain. J. Neurosci. 29 (14) 4531-4541.

Cuthbert, B.N., Insel, T.R., 2013. Toward the future of psychiatric diagnosis: the seven pillars of RDoC. BMC Med. 11 (1). https://doi.org/10.1186/1741-7015-11-126.

Czoty, P.W., Riddick, N.V., Gage, H.D., Sandridge, M., Nader, S.H., Garg, S., Bounds, M. Garg, P.K., Nader, M.A., 2009. Effect of menstrual cycle phase on dopamine D2 receptor availability in female cynomolgus monkeys. Neuropsychopharmacol 34 (3),
$548-554$.

Dalton, G.L., Wang, N.Y., Phillips, A.G., Floresco, S.B., 2016. Multifaceted contributions by different regions of the orbitofrontal and medial prefrontal cortex to probabilistic reversal learning. J. Neurosci. 36 (6), 1996-2006.

Dan, R., Canetti, L., Keadan, T., Segman, R., Weinstock, M., Bonne, O., Reuveni, I., Goelman, G., 2019. Sex differences during emotion processing are dependent on the menstrual cycle phase. Psychoneuroendocrinology 100, 85-95.

Daniel, J.M., Hulst, J.L., Berbling, J.L., 2006. Estradiol replacement enhances working memory in middle-aged rats when initiated immediately after ovariectomy but not after a long-term period of ovarian hormone deprivation. Endocrinology 147 (1), 607-614. https://doi.org/10.1210/en.2005-0998.

Davis, D.M., Jacobson, T.K., Aliakbari, S., Mizumori, S.J.Y., 2005. Differential effects of estrogen on hippocampal- and striatal-dependent learning. Neurobiol. Learn. Mem. 84 (2), 132-137.

Deakin, J.F., 1991. Depression and 5HT. Int. Clin. Psychopharmacol. 6 (Suppl 3), 23-28 discussion 29-31.

Del Río, J.P., Alliende, M.I., Molina, N., Serrano, F.G., Molina, S., Vigil, P., 2018. Steroid hormones and their action in women's brains: the importance of hormonal balance. Front. Public Health 6, 141. https://doi.org/10.3389/fpubh.2018.00141.

Delgado, M.R., Li, J., Schiller, D., Phelps, E.A., 2008. The role of the striatum in aversive learning and aversive prediction errors. Phil. Trans. R. Soc. B 363 (1511), 3787-3800.

Dell'Osso, L., Carmassi, C., Mucci, F., Marazziti, D., 2016. Depression, serotonin and tryptophan. Curr. Pharm. Des. 22 (8), 949-954.

Derntl, B., Pintzinger, N., Kryspin-Exner, I., Schopf, V., 2014. The impact of sex hormone concentrations on decision-making in females and males. Front. Neurosci. 8, 352. https://doi.org/10.3389/fnins.2014.00352.

Di Chiara, G., Tanda, G., Bassareo, V., Pontieri, F., Acquas, E., Fenu, S., Cadoni, C., Carboni, E., 1999. Drug addiction as a disorder of associative learning - Role of nucleus accumbens shell/extended amygdala dopamine. Ann. N. Y. Acad. Sci. 877, 461-485.

Dichter, G.S., Damiano, C.A., Allen, J.A., 2012. Reward circuitry dysfunction in psychiatric and neurodevelopmental disorders and genetic syndromes: animal models and clinical findings. J. Neurodev. Disord. 4 (1), 19. https://doi.org/10.1186/18661955-4-19.

Diekhof, E.K., 2015. Be quick about it. Endogenous estradiol level, menstrual cycle phase and trait impulsiveness predict impulsive choice in the context of reward acquisition. Horm. Behav. 74, 186-193.

Diekhof, E.K., 2018. Estradiol and the reward system in humans. Curr. Opin. Behav. Sci. 23, 58-64.

Diekhof, E.K., Reimers, L., Holtfrerich, S.K.C., 2018. Hormonal modulation of reinforcement learning and reward-related process - a role for $17 \beta$-estradiol, progesterone and testosterone. In: Schultheiss, O.C., Mehta, P.H. (Eds.), International Handbook of Social Neuroendocrinology. Routledge, London, UK.

Dölen, G., Darvishzadeh, A., Huang, K.W., Malenka, R.C., 2013. Social reward requires coordinated activity of nucleus accumbens oxytocin and serotonin. Nature 501 (7466), 179-184.

Dreher, J.-C., Schmidt, P.J., Kohn, P., Furman, D., Rubinow, D., Berman, K.F., 2007. Menstrual cycle phase modulates reward-related neural function in women. Proc. Natl. Acad. Sci. 104 (7), 2465-2470.

Drevets, W.C., 2000. Neuroimaging studies of mood disorders. Biol. Psychiatry 48 (8), 813-829.

Egan, M.F., Goldberg, T.E., Kolachana, B.S., Callicott, J.H., Mazzanti, C.M., Straub, R.E., Goldman, D., Weinberger, D.R., 2001. Effect of COMT Val108/158 Met genotype on frontal lobe function and risk for schizophrenia. Proc. Natl. Acad. Sci. 98 (12), 6917-6922.

Elman, I., Karlsgodt, K.H., Gastfriend, D.R., 2001. Gender differences in cocaine craving among non-treatment-seeking individuals with cocaine dependence. Am. J. Drug Alcohol Abuse 27 (2), 193-202. https://doi.org/10.1081/ada-100103705.

Epperson, C.N., Haga, K., Mason, G.F., Sellers, E., Gueorguieva, R., Zhang, W., Weiss, E., Rothman, D.L., Krystal, J.H., 2002. Cortical gamma-aminobutyric acid levels across the menstrual cycle in healthy women and those with premenstrual dysphoric disorder: a proton magnetic resonance spectroscopy study. Arch. Gen. Psychiatry 59 (9), 851-858. https://doi.org/10.1001/archpsyc.59.9.851.

Epperson, C.N., Steiner, M., Hartlage, S.A., Eriksson, E., Schmidt, P.J., Jones, I., Yonkers, K.A., 2012. Premenstrual dysphoric disorder: evidence for a new category for DSM-5. Am. J. Psychiatry 169 (5), 465-475.

Eshel, N., Roiser, J.P., 2010. Reward and punishment processing in depression. Biol. Psychiatry 68 (2), 118-124.

Evans, S.M., 2007. The role of estradiol and progesterone in modulating the subjective effects of stimulants in humans. Exp. Clin. Psychopharmacol. 15 (5), 418-426. https://doi.org/10.1037/1064-1297.15.5.418.

Evans, S.M., Foltin, R.W., 2006. Exogenous progesterone attenuates the subjective effects of smoked cocaine in women, but not in men. Neuropsychopharmacol 31 (3), 659-674.

Evans, S.M., Foltin, R.W., 2010. Does the response to cocaine differ as a function of sex or hormonal status in human and non-human primates? Horm. Behav. 58 (1), 13-21. https://doi.org/10.1016/j.yhbeh. 2009.08.010.

Evans, S., Haney, M., Foltin, R., 2002. The effects of smoked cocaine during the follicular and luteal phases of the menstrual cycle in women. Psychopharmacology 159 (4), 397-406.

Everitt, B.J., Robbins, T.W., 2005. Neural systems of reinforcement for drug addiction: from actions to habits to compulsion. Nat. Neurosci. 8 (11), 1481-1489.

Everitt, B.J., Wolf, M.E., 2002. Psychomotor stimulant addiction: a neural systems perspective. J. Neurosci. 22 (9), 3312-3320.

Faraji-Rad, A., Moeini-Jazani, M., Warlop, L., 2013. Women seek more variety in rewards 
when closer to ovulation. J. Consumer Psychol. 23 (4), 503-508.

Felten, D.L., Shetty, A.N., 2010. Netter's Atlas of Neuroscience. Elsevier, Philadelphia, PA. Feltenstein, M.W., See, R.E., 2007. Plasma progesterone levels and cocaine-seeking in freely cycling female rats across the estrous cycle. Drug Alcohol Depend. 89 (2-3), 183-189.

Felton, T.M., Auerbach, S.B., 2004. Changes in $\gamma$-aminobutyric acid tone and extracellular serotonin in the dorsal raphe nucleus over the rat estrous cycle. Neuroendocrinology 80 (3), 152-157. https://doi.org/10.1159/000082356.

Field, M., Duka, T., 2004. Cue reactivity in smokers: the effects of perceived cigarette availability and gender. Pharmacol. Biochem. Behav. 78 (3), 647-652.

Fischer, A.G., Ullsperger, M., 2017. An update on the role of serotonin and its interplay with dopamine for reward. Front. Hum. Neurosci. 11, 484. https://doi.org/10.3389/ fnhum. 2017.00484.

Forray, A., Gilstad-Hayden, K., Suppies, C., Bogen, D., Sofuoglu, M., Yonkers, K.A., 2017. Progesterone for smoking relapse prevention following delivery: a pilot, randomized, double-blind study. Psychoneuroendocrinology 86, 96-103.

Foy, M.R., Xu, J., Xie, X., Brinton, R.D., Thompson, R.F., Berger, T.W., 1999. 17betaestradiol enhances NMDA receptor-mediated EPSPs and long-term potentiation. J. Neurophysiol. 81 (2), 925-929. https://doi.org/10.1152/jn.1999.81.2.925.

Frank, M.J., Hutchison, K., 2009. Genetic contributions to avoidance-based decisions: striatal D2 receptor polymorphisms. Neuroscience 164 (1), 131-140.

Frank, T.C., Kim, G.L., Krzemien, A., Van Vugt, D.A., 2010. Effect of menstrual cycle phase on corticolimbic brain activation by visual food cues. Brain Res. 1363, 81-92.

Franklin, T.R., Jagannathan, K., Wetherill, R.R., Johnson, B., Kelly, S., Langguth, J., Mumma, J., Childress, A.R., 2015. Influence of menstrual cycle phase on neural and craving responses to appetitive smoking cues in naturally cycling females. Nicotine Tob. Res. 17 (4), 390-397.

Freeman, E.W., Sammel, M.D., Boorman, D.W., Zhang, R.M., 2014. Longitudinal pattern of depressive symptoms around natural menopause. JAMA Psychiatry 71 (1), 36-43. https://doi.org/10.1001/jamapsychiatry.2013.2819.

Galea, L.A.M., Wide, J.K., Barr, A.M., 2001. Estradiol alleviates depressive-like symptoms in a novel animal model of post-partum depression. Behav. Brain Res. 122 (1), 1-9.

Garg, D., Ng, S.S.M., Baig, K.M., Driggers, P., Segars, J., 2017. Progesterone-mediated non-classical signaling. Trends Endocrinol. Metab. 28 (9), 656-668.

Georgiou, P., Zanos, P., Bhat, S., Tracy, J.K., Merchenthaler, I.J., McCarthy, M.M., Gould, T.D., 2018. Dopamine and stress system modulation of sex differences in decision making. Neuropsychopharmacol. 43 (2), 313-324.

Geyer, M.A., Puerto, A., Dawsey, W.J., Knapp, S., Bullard, W.P., Mandell, A.J., 1976. Histologic and enzymatic studies of the mesolimbic and mesostriatal serotonergic pathways. Brain Res. 106 (2), 241-256.

Goldstein, R.Z., Craig, A.D.(., Bechara, A., Garavan, H., Childress, A.R., Paulus, M.P., Volkow, N.D., 2009. The neurocircuitry of impaired insight in drug addiction. Trends Cognit. Sci. 13 (9), 372-380.

Goschke, T., 2014. Dysfunctions of decision-making and cognitive control as transdiagnostic mechanisms of mental disorders: advances, gaps, and needs in current research: dysfunctions of decision-making and cognitive control. Int. J. Methods Psychiatr. Res. 23 (S1), 41-57.

Grant, B.F., Saha, T.D., Ruan, W.J., Goldstein, R.B., Chou, S.P., Jung, J.S., Zhang, H.T., Smith, S.M., Pickering, R.P., Huang, B.J., Hasin, D.S., 2016. Epidemiology of DSM-5 drug use disorder results from the national epidemiologic survey on alcohol and related conditions-III. JAMA Psychiatry 73 (1), 39-47. https://doi.org/10.1001/ jamapsychiatry.2015.2132.

Green, A.D., Barr, A.M., Galea, L.A.M., 2009. Role of estradiol withdrawal in 'anhedonic' sucrose consumption: a model of postpartum depression. Physiol. Behav. 97 (2) $259-265$.

Griskova-Bulanova, I., Griksiene, R., Voicikas, A., Ruksenas, O., 2016. Go and NoGo: modulation of electrophysiological correlates by female sex steroid hormones. Psychopharmacology 233 (13), 2607-2615.

Groman, S.M., Smith, N.J., Petrullli, J.R., Massi, B., Chen, L., Ropchan, J., Huang, Y., Lee, D., Morris, E.D., Taylor, J.R., 2016. Dopamine D 3 receptor availability is associated with inflexible decision making. J. Neurosci. 36 (25), 6732-6741.

Guillaume, S., Perroud, N., Jollant, F., Jaussent, I., Olié, E., Malafosse, A., Courtet, P. 2013. HPA axis genes may modulate the effect of childhood adversities on decisionmaking in suicide attempters. J. Psychiatr. Res. 47 (2), 259-265.

Guitart-Masip, M., Duzel, E., Dolan, R., Dayan, P., 2014. Action versus valence in decision making. Trends Cognit. Sci. 18 (4), 194-202.

Gulinello, M., Gong, Q.H., Li, X., Smith, S.S., 2001. Short-term exposure to a neuroactive steroid increases alpha4 GABA(A) receptor subunit levels in association with increased anxiety in the female rat. Brain Res. 910 (1-2), 55-66. https://doi.org/10. 1016/s0006-8993(01)02565-3.

Gundlah, C., Lu, N., Bethea, C., 2002. Ovarian steroid regulation of monoamine oxidase-A and $\mathrm{B}$ mRNAs in the macaque dorsal raphe and hypothalamic nuclei. Psychopharmacology 160 (3), 271-282.

Gundlah, C., Lu, N.Z., Mirkes, S.J., Bethea, C.L., 2001. Estrogen receptor beta (ERbeta) mRNA and protein in serotonin neurons of macaques. Brain Res. Mol. Brain Res. 91 (1-2), 14-22. https://doi.org/10.1016/s0169-328x(01)00108-5.

Guttman, Z., Moeller, S.J., London, E.D., 2018. Neural underpinnings of maladaptive decision-making in addictions. Pharmacol. Biochem. Behav. 164, 84-98.

Haber, S.N., Knutson, B., 2010. The reward circuit: linking primate anatomy and human imaging. Neuropsychopharmacol 35 (1), 4-26.

Hedges, V.L., Staffend, N.A., Meisel, R.L., 2010. Neural mechanisms of reproduction in females as a predisposing factor for drug addiction. Front. Neuroendocrinol. 31 (2), 217-231.

Hellgren, C., Bannbers, E., Åkerud, H., Risbrough, V., Sundström Poromaa, I., 2012. Decreased startle modulation during anticipation in the postpartum period in comparison to late pregnancy. Arch. Womens Ment. Health 15 (2), 87-94.
Helmbold, K., Zvyagintsev, M., Dahmen, B., Bubenzer-Busch, S., Gaber, T.J., Crockett, M.J., Klasen, M., Sánchez, C.L., Eisert, A., Konrad, K., Habel, U., Herpertz-Dahlmann, B., Zepf, F.D., 2015. Effects of serotonin depletion on punishment processing in the orbitofrontal and anterior cingulate cortices of healthy women. Eur. Neuropsychopharmacol. 25 (6), 846-856.

Hiroi, R., McDevitt, R.A., Neumaier, J.F., 2006. Estrogen selectively increases tryptophan hydroxylase-2 mRNA expression in distinct subregions of rat midbrain raphe nucleus: association between gene expression and anxiety behavior in the open field. Biol. Psychiatry 60 (3), 288-295.

Hiroi, R., Weyrich, G., Koebele, S., Mennenga, S., Talboom, J., Hewitt, L., Lavery, C., Mendoza, P., Jordan, A., Bimonte-Nelson, H., 2016. Benefits of hormone therapy estrogens depend on estrogen type: $17 \beta$-estradiol and conjugated equine estrogens have differential effects on cognitive, anxiety-like, and depressive-like behaviors and increase tryptophan hydroxylase-2 mRNA levels in dorsal raphe nucleus subregions. Front. Neurosci. 10, 517. https://doi.org/10.3389/fnins.2016.00517.

Holroyd, C.B., Coles, M.G.H., 2002. The neural basis of human error processing: reinforcement learning, dopamine, and the error-related negativity. Psychol. Rev. 109 (4), 679-709. https://doi.org/10.1037/0033-295X.109.4.679.

Holroyd, C.B., Pakzad-Vaezi, K.L., Krigolson, O.E., 2008. The feedback correct-related positivity: sensitivity of the event-related brain potential to unexpected positive feedback. Psychophysiology 45 (5), 688-697. https://doi.org/10.1111/j.1469-8986. 2008.00668.x.

Hornung, J.-P., 2003. The human raphe nuclei and the serotonergic system. J. Chem. Neuroanat. 26 (4), 331-343.

Hudson, A., Stamp, J.A., 2011. Ovarian hormones and propensity to drug relapse: a review. Neurosci. Biobehav. Rev. 35 (3), 427-436.

Hummel, T., Gollisch, R., Wildt, G., Kobal, G., 1991. Changes in olfactory perception during the menstrual cycle. Experientia 47 (7), 712-715.

Insel, T.R., 2014. The NIMH research domain criteria (RDoC) project: precision medicine for psychiatry. Am. J. Psychiatry 171 (4), 395-397.

Jakob, K., Ehrentreich, H., Holtfrerich, S.K.C., Reimers, L., Diekhof, E.K., 2018. DAT1genotype and menstrual cycle, but not hormonal contraception, modulate reinforcement learning: preliminary evidence. Front. Endocrinol. (Lausanne) 9, 60. https://doi.org/10.3389/fendo.2018.00060.

Justice, A.J.H., de Wit, H., 1999. Acute effects of d -amphetamine during the follicular and luteal phases of the menstrual cycle in women. Psychopharmacology 145 (1), 67-75.

Justice, A.J.H., De Wit, H., 2000. Acute effects of d-amphetamine during the early and late follicular phases of the menstrual cycle in women. Pharmacol. Biochem. Behav. 66 (3), 509-515.

Kasubuchi, M., Watanabe, K., Hirano, K., Inoue, D., Li, X., Terasawa, K., Konishi, M., Itoh, N., Kimura, I., 2017. Membrane progesterone receptor beta (mPRbeta/Paqr8) promotes progesterone-dependent neurite outgrowth in PC12 neuronal cells via non-G protein-coupled receptor (GPCR) signaling. Sci. Rep. 7 (1), 5168. https://doi.org/10. 1038/s41598-017-05423-9.

Keedwell, P.A., Andrew, C., Williams, S.C.R., Brammer, M.J., Phillips, M.L., 2005. The neural correlates of anhedonia in major depressive disorder. Biol. Psychiatry 58 (11), 843-853.

Keren, H., O'Callaghan, G., Vidal-Ribas, P., Buzzell, G.A., Brotman, M.A., Leibenluft, E., Pan, P.M., Meffert, L., Kaiser, A., Wolke, S., Pine, D.S., Stringaris, A., 2018. Reward processing in depression: a conceptual and meta-analytic review across fMRI and EEG studies. Am. J. Psychiatry 175 (11), 1111-1120.

Khani, A., Rainer, G., 2016. Neural and neurochemical basis of reinforcement-guided decision making. J. Neurophysiol. 116 (2), 724-741.

Kilts, C.D., Gross, R.E., Ely, T.D., Drexler, K.P.G., 2004. The neural correlates of cueinduced craving in cocaine-dependent women. Am. J. Psychiatry 161 (2), 233-241.

Kow, L.-M., Pfaff, D.W., 2018. Can distinctly different rapid estrogen actions share a common mechanistic step? Horm. Behav. 104, 156-164.

Kringelbach, M.L., 2005. The human orbitofrontal cortex: linking reward to hedonic experience. Nat. Rev. Neurosci. 6 (9), 691-702.

Krolick, K.N., Zhu, Q., Shi, H., 2018. Effects of estrogens on central nervous system neurotransmission: implications for sex differences in mental disorders. Prog. Mol. Biol. Transl. Sci. 160, 105-171. https://doi.org/10.1016/bs.pmbts.2018.07.008.

Kuehner, C., 2017. Why is depression more common among women than among men? Lancet Psychiatry 4 (2), 146-158.

Kumar, P., Goer, F., Murray, L., Dillon, D.G., Beltzer, M.L., Cohen, A.L., Brooks, N.H., Pizzagalli, D.A., 2018. Impaired reward prediction error encoding and striatal-midbrain connectivity in depression. Neuropsychopharmacol 43 (7), 1581-1588.

Laakso, A., Vilkman, H., Bergman, J.ö., Haaparanta, M., Solin, O., Syvälahti, E., Salokangas, R.K.R., Hietala, J., 2002. Sex differences in striatal presynaptic dopamine synthesis capacity in healthy subjects. Biol. Psychiatry 52 (7), 759-763.

Laflamme, N., Nappi, R.E., Drolet, G., Labrie, C., Rivest, S., 1998. Expression and neuropeptidergic characterization of estrogen receptors (ER $\alpha$ and ER $\beta$ ) throughout the rat brain: anatomical evidence of distinct roles of each subtype. J. Neurobiol. 36 (3), 357-378. https://doi.org/10.1002/(SICI)1098-2396(19991201)34:3<222::AID SYN6 $>$ 3.0.CO;2-J.

Lammers, C.-H., D'Souza, U., Qin, Z.-H., Lee, S.-H., Yajima, S., Mouradian, M.M., 1999. Regulation of striatal dopamine receptors by estrogen. Synapse 34 (3), 222-227. https://doi.org/10.1002/(SICI)1098-2396(19991201)34:3<222::AID-SYN6 > 3.0. CO;2-J.

Lawson, R.P., Seymour, B., Loh, E., Lutti, A., Dolan, R.J., Dayan, P., Weiskopf, N., Roiser, J.P., 2014. The habenula encodes negative motivational value associated with primary punishment in humans. Proc. Natl. Acad. Sci. 111 (32), 11858-11863.

Lazzaro, S.C., Rutledge, R.B., Burghart, D.R., Glimcher, P.W., 2016. The Impact of Menstrual Cycle Phase on Economic Choice and Rationality. PLoS One 11 (1), e0144080. https://doi.org/10.1371/journal.pone.0144080. 
Lee, T.M.C., Chan, C.C.H., Leung, A.W.S., Fox, P.T., Gao, J.-H., 2009. Sex-related differences in neural activity during risk taking: an fMRI study. Cereb. Cortex 19 (6), 1303-1312.

Leppänen, J.M., 2006. Emotional information processing in mood disorders: a review of behavioral and neuroimaging findings. Curr. Opin. Psychiatry 19 (1), 34-39.

Lévesque, D., Gagnon, S., Di Paolo, T., 1989. Striatal D1 dopamine receptor densitiy fluctuates during the rat estrous cycle. Neurosci. Lett. 98 (3), 345-350. https://doi. org/10.1016/0304-3940(89)90426-6.

Lévesque, D., Di Paolo, T., 1989. Chronic estradiol treatment increases ovariectomized rat striatal D-1 dopamine receptors. Life Sci. 45 (19), 1813-1820. https://doi.org/10. 1016/0024-3205(89)90522-5.

Lewis, C.A., Kimmig, A.S., Zsido, R.G., Jank, A., Derntl, B., Sacher, J., 2019. Effects of hormonal contraceptives on mood: a focus on emotion recognition and reactivity, reward processing, and stress response. Curr. Psychiatry Rep. 21 (11), 115. https:// doi.org/10.1007/s11920-019-1095-z.

Li, Y., Pehrson, A.L., Budac, D.P., Sánchez, C., Gulinello, M., 2012. A rodent model of premenstrual dysphoria: progesterone withdrawal induces depression-like behavior that is differentially sensitive to classes of antidepressants. Behav. Brain Res. 234 (2), 238-247.

Li, Y., Qiao, L., Sun, J., Wei, D., Li, W., Qiu, J., Zhang, Q., Shi, H., 2014. Gender-specific neuroanatomical basis of behavioral inhibition/approach systems (BIS/BAS) in a large sample of young adults: a voxel-based morphometric investigation. Behav. Brain Res. 274, 400-408.

Li, Y., Zhong, W., Wang, D., Feng, Q., Liu, Z., Zhou, J., Jia, C., Hu, F., Zeng, J., Guo, Q., $\mathrm{Fu}, \mathrm{L}$., Luo, M., 2016. Serotonin neurons in the dorsal raphe nucleus encode reward signals. Nat. Comm. 7 (1), 10503. https://doi.org/10.1038/ncomms10503.

Lighthall, N.R., Sakaki, M., Vasunilashorn, S., Nga, L., Somayajula, S., Chen, E.Y., Samii, N., Mather, M., 2012. Gender differences in reward-related decision processing under stress. Soc. Cogn. Affect Neurosci. 7 (4), 476-484. https://doi.org/10.1093/scan/ nsr026.

Lipatova, O., Byrd, D., Green, J.T., Toufexis, D.J., 2014. Effects of continuous vs. cycling estrogen replacement on the acquisition, retention and expression of place- and response-learning in the open-field tower maze. Neurobiol. Learn. Mem. 114, 81-89.

Liu, Z., Zhou, J., Li, Y.i., Hu, F., Lu, Y., Ma, M., Feng, Q., Zhang, J.-e., Wang, D., Zeng, J., Bao, J., Kim, J.-Y., Chen, Z.-F., El Mestikawy, S., Luo, M., 2014. Dorsal raphe neurons signal reward through 5-HT and glutamate. Neuron 81 (6), 1360-1374.

Lottem, E., Banerjee, D., Vertechi, P., Sarra, D., Lohuis, M.O., Mainen, Z.F., 2018. Activation of serotonin neurons promotes active persistence in a probabilistic foraging task. Nat. Comm. 9 (1), 1000. https://doi.org/10.1038/s41467-018-03438-y.

Lynch, W., Roth, M., Carroll, M., 2002. Biological basis of sex differences in drug abuse: preclinical and clinical studies. Psychopharmacology 164 (2), 121-137.

Macoveanu, J., Henningsson, S., Pinborg, A., Jensen, P., Knudsen, G.M., Frokjaer, V.G., Siebner, H.R., 2016. Sex-steroid hormone manipulation reduces brain response to reward. Neuropsychopharmacol 41 (4), 1057-1065.

Maejima, T., Masseck, O.A., Mark, M.D., Herlitze, S., 2013. Modulation of firing and synaptic transmission of serotonergic neurons by intrinsic G protein-coupled receptors and ion channels. Front. Integr. Neurosci. 7, 40. https://doi.org/10.3389/ fnint.2013.00040.

Majewska, M., Harrison, N., Schwartz, R., Barker, J., Paul, S., 1986. Steroid hormone metabolites are barbiturate-like modulators of the GABA receptor. Science 232 (4753), 1004-1007.

Malvaez, M., Shieh, C., Murphy, M.D., Greenfield, V.Y., Wassum, K.M., 2019. Distinct cortical-amygdala projections drive reward value encoding and retrieval. Nat. Neurosci. 22 (5), 762-769.

Mannella, P., Brinton, R.D., 2006. Estrogen receptor protein interaction with phosphatidylinositol 3-kinase leads to activation of phosphorylated Akt and extracellular signal-regulated kinase $1 / 2$ in the same population of cortical neurons: a unified mechanism of estrogen action. J. Neurosci. 26 (37), 9439-9447. https://doi.org/10. 1523/JNEUROSCI.1443-06.2006.

Mannisto, P.T., Kaakkola, S., 1999. Catechol-O-methyltransferase (COMT): biochemistry, molecular biology, pharmacology, and clinical efficacy of the new selective COMT inhibitors. Pharmacol. Rev. 51 (4), 593-628.

Marino, M., Galluzzo, P., Ascenzi, P., 2006. Estrogen signaling multiple pathways to impact gene transcription. Curr. Genomics 7 (8), 497-508. https://doi.org/10.2174/ 138920206779315737.

Marx, C.E., Keefe, R.S.E., Buchanan, R.W., Hamer, R.M., Kilts, J.D., Bradford, D.W., Strauss, J.L., Naylor, J.C., Payne, V.M., Lieberman, J.A., Savitz, A.J., Leimone, L.A., Dunn, L., Porcu, P., Morrow, A.L., Shampine, L.J., 2009. Proof-of-concept trial with the neurosteroid pregnenolone targeting cognitive and negative symptoms in schizophrenia. Neuropsychopharmacol 34 (8), 1885-1903.

Matias, S., Lottem, E., Dugué, G.P., Mainen, Z.F., 2017. Activity patterns of serotonin neurons underlying cognitive flexibility. Elife 6, e20552. https://doi.org/10.7554/ eLife.20552.

McEwen, B.S., Alves, S.E., 1999. Estrogen actions in the central nervous system. Endocr. Rev. 20 (3), 279-307. https://doi.org/10.1210/edrv.20.3.0365.

McKee, S.A., Smith, P.H., Kaufman, M., Mazure, C.M., Weinberger, A.H., 2016. Sex differences in varenicline efficacy for smoking cessation: a meta-analysis. Nic. Tob Res. 18 (5), 1002-1011.

Medford, N., Critchley, H.D., 2010. Conjoint activity of anterior insular and anterior cingulate cortex: awareness and response. Brain Struct. Funct. 214 (5-6), 535-549.

Meffre, D., Labombarda, F., Delespierre, B., Chastre, A., De Nicola, A.F., Stein, D.G., Schumacher, M., Guennoun, R., 2013. Distribution of membrane progesterone receptor alpha in the male mouse and rat brain and its regulation after traumatic brain injury. Neuroscience 231, 111-124.

Mehta, P.H., Welker, K.M., Zilioli, S., Carré, J.M., 2015. Testosterone and cortisol jointly modulate risk-taking. Psychoneuroendocrinology 56, 88-99.
Mello, N.K., 2010. Hormones, nicotine, and cocaine: clinical studies. Horm. Behav. 58 (1), $57-71$

Meneses, A., 1999. 5-HT system and cognition. Neurosci. Biobehav. Rev. 23 (8), 1111-1125.

Meneses, A., Perez-Garcia, G., 2007. 5-HT1A receptors and memory. Neurosci. Biobehav. Rev. 31 (5), 705-727.

Mitra, S.W., Hoskin, E., Yudkovitz, J., Pear, L., Wilkinson, H.A., Hayashi, S., Pfaff, D.W., Ogawa, S., Rohrer, S.P., Schaeffer, J.M., McEwen, B.S., Alves, S.E., 2003. Immunolocalization of estrogen receptor $\beta$ in the mouse brain: comparison with estrogen receptor $\alpha$. Endocrinology 144 (5), 2055-2067. https://doi.org/10.1210/en. 2002-221069.

Miyazaki, K., Miyazaki, K.W., Doya, K., 2012. The role of serotonin in the regulation of patience and impulsivity. Mol. Neurobiol. 45 (2), 213-224.

Miyazaki, K., Miyazaki, K.W., Yamanaka, A., Tokuda, T., Tanaka, K.F., Doya, K., 2018. Reward probability and timing uncertainty alter the effect of dorsal raphe serotonin neurons on patience. Nat. Comm. 9 (1), 2048. https://doi.org/10.1038/s41467-01804496-y.

Moran, R.J., Kishida, K.T., Lohrenz, T., Saez, I., Laxton, A.W., Witcher, M.R., Tatter, S.B., Ellis, T.L., Phillips, P.EM., Dayan, P., Montague, P.R., 2018. The Protective Action Encoding of Serotonin Transients in the Human Brain. Neuropsychopharmacol. 43 (6), 1425-1435.

Morgan, J.K., Olino, T.M., McMakin, D.L., Ryan, N.D., Forbes, E.E., 2013. Neural response to reward as a predictor of increases in depressive symptoms in adolescence. Neurobiol. Dis. 52, 66-74.

Mulligan, E.M., Nelson, B.D., Infantolino, Z.P., Luking, K.R., Sharma, R., Hajcak, G., 2018. Effects of menstrual cycle phase on electrocortical response to reward and depressive symptoms in women. Psychophysiology 55 (12), e13268. https://doi.org/10.1111/ psyp.2018.55.issue-1210.1111/psyp.13268.

Munk-Olsen, T., Laursen, T.M., Pedersen, C.B., Mors, O., Mortensen, P.B., 2006. New parents and mental disorders: a population-based register study. JAMA 296 (21), 2582-2589. https://doi.org/10.1001/jama.296.21.2582.

Munro, C.A., McCaul, M.E., Wong, D.F., Oswald, L.M., Zhou, Y., Brasic, J., Kuwabara, H., Kumar, A., Alexander, M., Ye, W., Wand, G.S., 2006. Sex differences in striatal dopamine release in healthy adults. Biol. Psychiatry 59 (10), 966-974.

Murray, E.A., 2007. The amygdala, reward and emotion. Trends Cognit. Sci. 11 (11), 489-497.

Nakamura, K., Matsumoto, M., Hikosaka, O., 2008. Reward-dependent modulation of neuronal activity in the primate dorsal raphe nucleus. J. Neurosci. 28 (20), 5331-5343.

Naqvi, N.H., Bechara, A., 2010. The insula and drug addiction: an interoceptive view of pleasure, urges, and decision-making. Brain Struct. Funct. 214 (5-6), 435-450.

Nelson, B.D., Perlman, G., Klein, D.N., Kotov, R., Hajcak, G., 2016. Blunted neural response to rewards as a prospective predictor of the development of depression in adolescent girls. Am. J. Psychiatry 173 (12), 1223-1230.

Nelson, J.A., 2016. Not-So-Strong Evidence for Gender Differences in Risk Taking. Feminist Econ. 22 (2), 114-142.

Nestler, E., 2002a. Common Molecular and Cellular Substrates of Addiction and Memory. Neurobiol. Learn. Mem. 78 (3), 637-647.

Nestler, E.J., 2002b. From neurobiology to treatment: progress against addiction. Nat. Neurosci. 5 (S11), 1076-1079.

O'Doherty, J.P., Cockburn, J., Pauli, W.M., 2017. Learning, reward, and decision making. Annu. Rev. Psychol. 68 (1), 73-100.

Op de Macks, Z.A., Bunge, S.A., Bell, O.N., Wilbrecht, L., Kriegsfeld, L.J., Kayser, A.S. Dahl, R.E., 2016. Risky decision-making in adolescent girls: the role of pubertal hormones and reward circuitry. Psychoneuroendocrinology 74, 77-91.

Orsini, C.A., Setlow, B., 2017. Sex differences in animal models of decision making. J. Neurosci. Res. 95 (1-2), 260-269. https://doi.org/10.1002/jnr.23810.

Orsini, C.A., Willis, M.L., Gilbert, R.J., Bizon, J.L., Setlow, B., 2016. Sex differences in a rat model of risky decision making. Behav. Neurosci. 130 (1), 50-61. https://doi.org/ 10.1037/bne0000111.

Ossewaarde, L., van Wingen, G.A., Kooijman, S.C., Backstrom, T., Fernandez, G., Hermans, E.J., 2011. Changes in functioning of mesolimbic incentive processing circuits during the premenstrual phase. Soc. Cogn. Affect. Neurosci. 6 (5), 612-620. https://doi.org/10.1093/scan/nsq071.

Österlund, M.K., Hurd, Y.L., 2001. Estrogen receptors in the human forebrain and the relation to neuropsychiatric disorders. Prog. Neurobiol. 64 (3), 251-267.

Overman, W.H., Frassrand, K., Ansel, S., Trawalter, S., Bies, B., Redmond, A., 2004 Performance on the IOWA card task by adolescents and adults. Neuropsychologia 42 (13), 1838-1851.

Owesson-White, C.A., Ariansen, J., Stuber, G.D., Cleaveland, N.A., Cheer, J.F., Wightman, R.M., Carelli, R.M., 2009. Neural encoding of cocaine-seeking behavior is coincident with phasic dopamine release in the accumbens core and shell. Eur. J. Neurosci. 30 (6), 1117-1127. https://doi.org/10.1111/j.1460-9568.2009.06916.x.

Padoa-Schioppa, C., Conen, K.E., 2017. Orbitofrontal cortex: a neural circuit for economic decisions. Neuron 96 (4), 736-754.

Palminteri, S., Khamassi, M., Joffily, M., Coricelli, G., 2015. Contextual modulation of value signals in reward and punishment learning. Nat. Comm. 6 (1), 8096. https:// doi.org/10.1038/ncomms9096.

Pan, P.M., Sato, J.R., Salum, G.A., Rohde, L.A., Gadelha, A., Zugman, A., Mari, J., Jackowski, A., Picon, F., Miguel, E.C., Pine, D.S., Leibenluft, E., Bressan, R.A., Stringaris, A., 2017. Ventral striatum functional connectivity as a predictor of adolescent depressive disorder in a longitudinal community-based sample. Am. J. Psychiatry 174 (11), 1112-1119.

Pasqualini, C., Olivier, V., Guibert, B., Frain, O., Leviel, V., 1995. Acute stimulatory effect of estradiol on striatal dopamine synthesis. J. Neurochem. 65 (4), 1651-1657.

Peper, J.S., Braams, B.R., Blankenstein, N.E., Bos, M.G.N., Crone, E.A., 2018. 
Development of multifaceted risk taking and the relations to sex steroid hormones: a longitudinal study. Child Dev. 89 (5), 1887-1907.

Perkins, K.A., Gerlach, D., Vender, J., Grobe, J., Meeker, J., Hutchison, S., 2001. Sex differences in the subjective and reinforcing effects of visual and olfactory cigarette smoke stimuli. Nicotine Tob. Res. 3 (2), 141-150. https://doi.org/10.1080/ 14622200110043059.

Pérez, S.E., Chen, E.Y., Mufson, E.J., 2003. Distribution of estrogen receptor alpha and beta immunoreactive profiles in the postnatal rat brain. Develop. Brain Res. 145 (1), 117-139.

Perlman, W.R., Matsumoto, M., Beltaifa, S., Hyde, T.M., Saunders, R.C., Webster, M.J., Rubinow, D.R., Kleinman, J.E., Weickert, C.S., 2005. Expression of estrogen receptor alpha exon-deleted mRNA variants in the human and non-human primate frontal cortex. Neuroscience 134 (1), 81-95.

Perry, C.J., Zbukvic, I., Kim, J.H., Lawrence, A.J., 2014. Role of cues and contexts on drug-seeking behaviour: cues, contexts and drug seeking. Br. J. Pharmacol. 171 (20), 4636-4672.

Phillips, G.D., Setzu, E., Vugler, A., Hitchcott, P.K., 2003. Immunohistochemical assessment of mesotelencephalic dopamine activity during the acquisition and expression of Pavlovian versus instrumental behaviours. Neuroscience 117 (3), 755-767.

Pierce, R.C., Kumaresan, V., 2006. The mesolimbic dopamine system: the final common pathway for the reinforcing effect of drugs of abuse? Neurosci. Biobehav. Rev. 30 (2), 215-238.

Pohjalainen, T., Rinne, J.O., Nagren, K., Syvälahti, E., Hietala, J., 1998. Sex differences in the striatal dopamine D2 receptor binding characteristics in vivo. Am. J. Psychiatry 155 (6), 768-773. https://doi.org/10.1176/ajp.155.6.768.

Protopopescu, X., Pan, H., Altemus, M., Tuescher, O., Polanecsky, M., McEwen, B., Silbersweig, D., Stern, E., 2005. Orbitofrontal cortex activity related to emotional processing changes across the menstrual cycle. Proc. Natl. Acad. Sci. 102 (44), 16060-16065.

Proudfit, G.H., 2015. The reward positivity: From basic research on reward to a biomarker for depression: the reward positivity. Psychophysiol 52 (4), 449-459.

Rangel, A., Camerer, C., Montague, P.R., 2008. A framework for studying the neurobiology of value-based decision making. Nat. Rev. Neurosci. 9 (7), 545-556.

Reavis, R., Overman, W.H., 2001. Adult sex differences on a decision-making task previously shown to depend on the orbital prefrontal cortex. Behav. Neurosci. 115 (1), 196-206. https://doi.org/10.1037/0735-7044.115.1.196.

Redish, A.D., 2004. Addiction as a Computational Process Gone Awry. Science 306 (5703), 1944-1947.

Reed, S.C., Evans, S.M., Bedi, G., Rubin, E., Foltin, R.W., 2011. The effects of oral micronized progesterone on smoked cocaine self-administration in women. Horm. Behav. 59 (2), 227-235.

Reimers, L., Buchel, C., Diekhof, E.K., 2014. How to be patient. The ability to wait for a reward depends on menstrual cycle phase and feedback-related activity. Front. Neurosci. 8, 401. https://doi.org/10.3389/fnins.2014.00401.

Robbins, S.J., Ehrman, R.N., Childress, A.R., O'Brien, C.P., 1999. Comparing levels of cocaine cue reactivity in male and female outpatients. Drug Alcohol Depend. 53 (3), 223-230.

Roberts, G.M.P., Newell, F., Simões-Franklin, C., Garavan, H., 2008. Menstrual cycle phase modulates cognitive control over male but not female stimuli. Brain Res. 1224, 79-87.

Rushworth, M.FS., Kolling, N., Sallet, J., Mars, R.B., 2012. Valuation and decision-making in frontal cortex: one or many serial or parallel systems? Curr. Opin. Neurobiol. 22 (6), 946-955.

Sacher, J., Neumann, J., Okon-Singer, H., Gotowiec, S., Villringer, A., 2013. Sexual dimorphism in the human brain: evidence from neuroimaging. Magn. Reson. Imaging 31 (3), 366-375.

Saga, Y., Tremblay, L., 2017. Dreher, J.-C., Tremblay, L. (Eds.), Chapter 4 - Ventral Striatopallidal Pathways Involved in Appetitive and Aversive Motivational Processes. Decision Neuroscience. Academic Press, San Diego, pp. 47-58. https://doi.org/10. 1016/B978-0-12-805308-9.00004-X.

Sambrook, T.D., Goslin, J., 2015. A neural reward prediction error revealed by a metaanalysis of ERPs using great grand averages. Psychol. Bull. 141 (1), 213-235. https:// doi.org/10.1037/bul0000006.

Schank, J.C., 2000. Menstrual-cycle variability and measurement: further cause for doubt. Psychoneuroendocrinology 25 (8), 837-847.

Schiller, C.E., O'Hara, M.W., Rubinow, D.R., Johnson, A.K., 2013. Estradiol modulates anhedonia and behavioral despair in rats and negative affect in a subgroup of women at high risk for postpartum depression. Physiol. Behav. 119, 137-144.

Schultz, W., 1997. Dopamine neurons and their role in reward mechanisms. Curr. Opin. Neurobiol. 7 (2), 191-197.

Schultz, W., Dayan, P., Montague, P.R., 1997. A neural substrate of prediction and reward. Science 275 (5306), 1593-1599.

Sell, L.A., Morris, J., Bearn, J., Frackowiak, R.S.J., Friston, K.J., Dolan, R.J., 1999. Activation of reward circuitry in human opiate addicts: reward circuitry in human opiate addicts. Eur. J. Neurosci. 11 (3), 1042-1048.

Shelton, A.L., Marchette, S.A., Furman, A.J., 2013. Chapter Six - A mechanistic approach to individual differences in spatial learning, memory, and navigation. In: Ross, B.H. (Ed.), Psychology of Learning and Motivation. Academic Press, vol. 59, pp. 223-259. https://doi.org/10.1016/B978-0-12-407187-2.00006-X.

Simerly, R.B., Swanson, L.W., Chang, C., Muramatsu, M., 2009. Distribution of androgen and estrogen receptor mRNA-containing cells in the rat brain: an in situ hybridization study. J. Comparat. Neurol. 294 (1), 76-95.

Singer, T., Critchley, H.D., Preuschoff, K., 2009. A common role of insula in feelings, empathy and uncertainty. Trends Cognit. Sci. 13 (8), 334-340.

Sinha, R., 2011. New findings on biological factors predicting addiction relapse vulnerability. Curr. Psychiatry Rep. 13 (5), 398-405.
Sinha, R., Fox, H., Hong, K.I., Sofuoglu, M., Morgan, P.T., Bergquist, K.T., 2007. Sex steroid hormones, stress response, and drug craving in cocaine-dependent women: implications for relapse susceptibility. Exp. Clin. Psychopharmacol. 15 (5), 445-452. https://doi.org/10.1037/1064-1297.15.5.445.

Smethells, J.R., Swalve, N.L., Eberly, L.E., Carroll, M.E., 2016. Sex differences in the reduction of impulsive choice (delay discounting) for cocaine in rats with atomoxetine and progesterone. Psychopharmacology 233 (15-16), 2999-3008.

Smith, C.T., Sierra, Y., Oppler, S.H., Boettiger, C.A., 2014. Ovarian cycle effects on immediate reward selection bias in humans: a role for estradiol. J. Neurosci. 34 (16), 5468-5476.

Smith, P.H., Bessette, A.J., Weinberger, A.H., Sheffer, C.E., McKee, S.A., 2016. Sex/ gender differences in smoking cessation: a review. Prev. Med. 92, 135-140.

Sofuoglu, M., Dudish-Poulsen, S., Nelson, D., Pentel, P.R., Hatsukami, D.K., 1999. Sex and menstrual cycle differences in the subjective effects from smoked cocaine in humans. Exp. Clin. Psychopharmacol. 7 (3), 274-283.

Soubrié, P., 1986. Reconciling the role of central serotonin neurons in human and animal behavior. Behav. Brain Sci. 9 (2), 319-335.

Srivastava, D.P., Evans, P.D., 2013. G-protein oestrogen receptor 1: Trials and tribulations of a membrane oestrogen receptor. J. Neuroendocrinol. 25 (11), 1219-1230.

Stanton, S.J., Mullette-Gillman, O.A., McLaurin, R.E., Kuhn, C.M., LaBar, K.S., Platt, M.L., Huettel, S.A., 2011. Low- and high-testosterone individuals exhibit decreased aversion to economic risk. Psychol. Sci. 22 (4), 447-453.

Stoltenberg, S.F., Lehmann, M.K., Anderson, C., Nag, P., Anagnopoulos, C., 2011. Serotonin transporter (5-HTTLPR) genotype and childhood traume are associated with individual differences in decision making. Front. Genet. 2, 33. https://doi.org/ 10.3389/fgene.2011.00033.

Stringaris, A., Vidal-Ribas Belil, P., Artiges, E., Lemaitre, H., Gollier-Briant, F., Wolke, S., Vulser, H., Miranda, R., Penttilä, J., Struve, M., Fadai, T., Kappel, V., Grimmer, Y., Goodman, R., Poustka, L., Conrod, P., Cattrell, A., Banaschewski, T., Bokde, A.L.W., Bromberg, U., Büchel, C., Flor, H., Frouin, V., Gallinat, J., Garavan, H., Gowland, P., Heinz, A., Ittermann, B., Nees, F., Papadopoulos, D., Paus, T., Smolka, M.N., Walter, H., Whelan, R., Martinot, J.-L., Schumann, G., Paillère-Martinot, M.-L., 2015. The brain's response to reward anticipation and depression in adolescence: dimensionality, specificity, and longitudinal predictions in a community-based sample. Am. J. Psychiatry 172 (12), 1215-1223.

Stuhrmann, A., Dohm, K., Kugel, H., Zwanzger, P., Redlich, R., Grotegerd, D., Rauch, A., Arolt, V., Heindel, W., Suslow, T., Zwitserlood, P., Dannlowski, U., 2013. Moodcongruent amygdala responses to subliminally presented facial expressions in major depression: associations with anhedonia. J. Psychiatry Neurosci. 38 (4), 249-258.

Sugiyama, N., Barros, R.P., Warner, M., Gustafsson, J.A., 2010. ERbeta: recent understanding of estrogen signaling. Trends Endocrinol. Metab. 21 (9), 545-552. https:// doi.org/10.1016/j.tem.2010.05.001.

Sukolová, D., Sarmány-Schuller, I., 2011. Fluctuating perception of selected risk situations with respect to hormonal changes during menstrual cycle. Studia Psychol. 53 (1), 3-12.

Sumner, B.E.H., Fink, G., 1998. Testosterone as well as estrogen increases serotonin2A receptor mRNA and binding site densities in the male rat brain. Mol. Brain Res. 59 (2), 205-214.

Sundström Poromaa, I., Gingnell, M., 2014. Menstrual cycle influence on cognitive function and emotion processing-from a reproductive perspective. Front. Neurosci. 8, 380. https://doi.org/10.3389/fnins.2014.00380.

Sutterer, M.J., Koscik, T.R., Tranel, D., 2015. Sex-related functional asymmetry of the ventromedial prefrontal cortex in regard to decision-making under risk and ambiguity. Neuropsychologia 75, 265-273.

Swalve, N., Smethells, J.R., Carroll, M.E., 2016. Progesterone attenuates impulsive action in a Go/No-Go task for sucrose pellets in female and male rats. Horm. Behav. 85, 43-47.

Swalve, N., Smethells, J.R., Younk, R., Mitchell, J., Dougen, B., Carroll, M.E., 2018. Sexspecific attenuation of impulsive action by progesterone in a go/no-go task for cocaine in rats. Psychopharmacology 235 (1), 135-143.

Terner, J.M., de Wit, H., 2006. Menstrual cycle phase and responses to drugs of abuse in humans. Drug Alcohol Depend. 84 (1), 1-13.

Thibeault, K.C., Kutlu, M.G., Sanders, C., Calipari, E.S., 2019. Cell-type and projectionspecific dopaminergic encoding of aversive stimuli in addiction. Brain Res. 1713, $1-15$.

Thomas, J., Météreau, E., Déchaud, H., Pugeat, M., Dreher, J.-C., 2014. Hormonal treatment increases the response of the reward system at the menopause transition: a counterbalanced randomized placebo-controlled fMRI study. Psychoneuroendocrinology 50, 167-180.

Thompson, T.L., Moss, R.L., 1994. Estrogen regulation of dopamine release in the nucleus accumbens: genomic-and nongenomic-mediated effects. J. Neurochem. 62 (5), 1750-1756. https://doi.org/10.1046/j.1471-4159.1994.62051750.x.

Tobia, M.J., Guo, R., Schwarze, U., Boehmer, W., Gläscher, J., Finckh, B., Marschner, A., Büchel, C., Obermayer, K., Sommer, T., 2014. Neural systems for choice and valuation with counterfactual learning signals. NeuroImage 89, 57-69.

Tonn Eisinger, K.R., Larson, E.B., Boulware, M.I., Thomas, M.J., Mermelstein, P.G., 2018. Membrane estrogen receptor signaling impacts the reward circuitry of the female brain to influence motivated behaviors. Steroids 133, 53-59.

Tosun, N.L., Fieberg, A.M., Eberly, L.E., Harrison, K.A., Tipp, A.R., Allen, A.M., Allen, S.S., 2019. Exogenous progesterone for smoking cessation in men and women: a pilot double-blind, placebo-controlled randomized clinical trial. Addiction 114 (10), $1800-1813$.

Tranel, D., Bechara, A., 2009. Sex-related functional asymmetry of the amygdala: preliminary evidence using a case-matched lesion approach. Neurocase 15 (3), 217-234.

Tranel, D., Damasio, H., Denburg, N.L., Bechara, A., 2005. Does gender play a role in functional asymmetry of ventromedial prefrontal cortex? Brain 128 (12), 2872-2881. 
https://doi.org/10.1093/brain/awh643.

Tucci, S.A., Murphy, L.E., Boyland, E.J., Dye, L., Halford, J.C.G., 2010. Oral contraceptive effects on food choice during the follicular and luteal phases of the menstrual cycle. A laboratory based study. Appetite 55 (3), 388-392.

Tunbridge, E.M., Harrison, P.J., Weinberger, D.R., 2006. Catechol-o-methyltransferase, cognition, and psychosis: Val158Met and beyond. Biol. Psychiatry 60 (2), 141-151.

Tversky, A., Kahneman, D., 1989. Rational choice and the framing of decisions. In Karpak, B., Zionts, S. (Eds.), Multiple Criteria Decision Making and Risk Analysis Using Microcomputers. Springer, Berlin Heidelberg, pp. 81-126.

Uban, K.A., Rummel, J., Floresco, S.B., Galea, L.A.M., 2012. Estradiol modulates effortbased decision making in female rats. Neuropsychopharmacol 37 (2), 390-401.

van den Bos, R., den Heijer, E., Vlaar, S., Houx, B., 2007. Exploring gender differences in decision-making using the Iowa Gambling Task. Psychology of Decision Making in Education, Behavior \& High Risk Situations, Nova Science Publishers Inc., pp. 207-226.

van den Bos, R., Homberg, J., de Visser, L., 2013. A critical review of sex differences in decision-making tasks: Focus on the Iowa Gambling Task. Behav. Brain Res. 238, 95-108.

van Wingen, G.A., van Broekhoven, F., Verkes, R.J., Petersson, K.M., Bäckström, T., Buitelaar, J.K., Fernández, G., 2008. Progesterone selectively increases amygdala reactivity in women. Mol. Psychiatry 13 (3), 325-333.

Vandegrift, B.J., You, C., Satta, R., Brodie, M.S., Lasek, A.W., 2017. Estradiol increases the sensitivity of ventral tegmental area dopamine neurons to dopamine and ethanol. PLoS One 12 (11), e0187698. https://doi.org/10.1371/journal.pone.0187698.

Vasudevan, N., Pfaff, D.W., 2008. Non-genomic actions of estrogens and their interaction with genomic actions in the brain. Front. Neuroendocrinol. 29 (2), 238-257.

Verharen, J.P.H., den Ouden, H.E.M., Adan, R.A.H., Vanderschuren, L.J.M.J., 2020. Modulation of value-based decision making behavior by subregions of the rat prefrontal cortex. Psychopharmacology 237 (5), 1267-1280.

Victor, T.A., Furey, M.L., Fromm, S.J., Ohman, A., Drevets, W.C., 2010. Relationship between amygdala responses to masked faces and mood state and treatment in major depressive disorder. Arch. Gen. Psychiatry 67 (11), 1128-1138. https://doi.org/10. 1001/archgenpsychiatry.2010.144.

Volkow, N.D., Fowler, J.S., Wang, G.-J., Swanson, J.M., 2004. Dopamine in drug abuse and addiction: results from imaging studies and treatment implications. Mol. Psychiatry 9 (6), 557-569.

Volkow, N.D., Wang, G.-J., Telang, F., Fowler, J.S., Logan, J., Childress, A.-R., Jayne, M., Ma, Y., Wong, C., 2006. Cocaine cues and dopamine in dorsal striatum: mechanism of craving in cocaine addiction. J. Neurosci. 26 (24), 6583-6588.

Walker, S.C., Robbins, T.W., Roberts, A.C., 2008. Differential contributions of dopamine and serotonin to orbitofrontal cortex function in the marmoset. Cereb. Cortex 19 (4), 889-898.

Wallin, K.G., Alves, J.M., Wood, R.I., 2015. Anabolic-androgenic steroids and decision making: probability and effort discounting in male rats. Psychoneuroendocrinology 57, 84-92.

Wallin-Miller, K.G., Chesley, J., Castrillon, J., Wood, R.I., 2017. Sex differences and hormonal modulation of ethanol-enhanced risk taking in rats. Drug Alcohol Depend. 174, 137-144.

Walsh, M.M., Anderson, J.R., 2012. Learning from experience: Event-related potential correlates of reward processing, neural adaptation, and behavioral choice. Neurosci. Biobehav. Rev. 36 (8), 1870-1884.

Walton, N., Maguire, J., 2019. Allopregnanolone-based treatments for postpartum depression: why/how do they work? Neurobiol. Stress 11, 100198. https://doi.org/10. 1016/j.ynstr.2019.100198.

Wang, S., Hu, S.-H., Shi, Y.i., Li, B.-M., 2017. The roles of the anterior cingulate cortex and its dopamine receptors in self-paced cost-benefit decision making in rats. Learn. Behav. 45 (1), 89-99.

Wang, V.C., Sable, H.J.K., Ju, Y.H., Allred, C.D., Helferich, W.G., Korol, D.L., Schantz, S.L., 2008. Effects of chronic estradiol treatment on delayed spatial alternation and differential reinforcement of low rates of responding. Behav. Neurosci. 122 (4),
794-804. https://doi.org/10.1037/a0012513.

Westbrook, A., Lamichhane, B., Braver, T., 2019. The subjective value of cognitive effort is encoded by a domain-general valuation network. J. Neurosci. 39 (20), 3934-3947.

Wetherill, R.R., Young, K.A., Jagannathan, K., Shin, J., O’Brien, C.P., Childress, A.R., Franklin, T.R., 2013. The impact of sex on brain responses to smoking cues: a perfusion fMRI study. Biol. Sex Dif. 4 (1), 9. https://doi.org/10.1186/2042-6410-4-9.

Wetter, D.W., Kenford, S.L., Smith, S.S., Fiore, M.C., Jorenby, D.E., Baker, T.B., 1999. Gender differences in smoking cessation. J. Consult. Clin. Psychol. 67 (4), 555-562.

White, T.L., Justice, A.J.H., de Wit, H., 2002. Differential subjective effects of d-amphetamine by gender, hormone levels and menstrual cycle phase. Pharmacol. Biochem. Behav. 73 (4), 729-741.

Willing, J., Wagner, C.K., 2016. Progesterone receptor expression in the developing mesocortical dopamine pathway: importance for complex cognitive behavior in adulthood. Neuroendocrinology 103 (3-4), 207-222. https://doi.org/10.1159/ 000434725 .

Wilson, S.J., Sayette, M.A., Fiez, J.A., 2004. Prefrontal responses to drug cues: a neurocognitive analysis. Nat. Neurosci. 7 (3), 211-214.

Wittchen, H.U., Jacobi, F., Rehm, J., Gustavsson, A., Svensson, M., Jönsson, B., Olesen, J., Allgulander, C., Alonso, J., Faravelli, C., Fratiglioni, L., Jennum, P., Lieb, R., Maercker, A., van Os, J., Preisig, M., Salvador-Carulla, L., Simon, R., Steinhausen, H. C., 2011. The size and burden of mental disorders and other disorders of the brain in Europe 2010. Eur. Neuropsychopharmacol. 21 (9), 655-679.

Xiao, L.i., Becker, J.B., 1994. Quantitative microdialysis determination of extracellular striatal dopamine concentration in male and female rats: effects of estrous cycle and gonadectomy. Neurosci. Lett. 180 (2), 155-158.

Xiao, X., Yang, Y., Zhang, Y., Zhang, X.M., Zhao, Z.Q., Zhang, Y.Q., 2013. Estrogen in the anterior cingulate cortex contributes to pain-related aversion. Cereb. Cortex 23 (9), 2190-2203. https://doi.org/10.1093/cercor/bhs201.

Yankova, M., Hart, S.A., Woolley, C.S., 2001. Estrogen increases synaptic connectivity between single presynaptic inputs and multiple postsynaptic CA1 pyramidal cells: a serial electron-microscopic study. Proc. Natl. Acad. Sci. 98 (6), 3525-3530.

Yen, J.-Y., Tu, H.-P., Chen, C.-S., Yen, C.-F., Long, C.-Y., Ko, C.-H., 2014. The effect of serotonin $1 \mathrm{~A}$ receptor polymorphism on the cognitive function of premenstrual dysphoric disorder. Eur. Arch. Psychiatry Clin. Neurosci. 264 (8), 729-739.

Yoest, K.E., Cummings, J.A., Becker, J.B., 2014. Estradiol, dopamine and motivation. Cent. Nerv. Syst. Agents Med. Chem. 14 (2), 83-89.

Yoest, K.E., Quigley, J.A., Becker, J.B., 2018. Rapid effects of ovarian hormones in dorsal striatum and nucleus accumbens. Horm. Behav. 104, 119-129.

Yokomaku, D., Numakawa, T., Numakawa, Y., Suzuki, S., Matsumoto, T., Adachi, N., Nishio, C., Taguchi, T., Hatanaka, H., 2003. Estrogen enhances depolarization-induced glutamate release through activation of phosphatidylinositol 3-kinase and mitogen-activated protein kinase in cultured hippocampal neurons. Mol. Endocrinol. 17 (5), 831-844.

Zhang, J.Q., Cai, W.Q., Zhou, D.S., Su, B.Y., 2002. Distribution and differences of estrogen receptor beta immunoreactivity in the brain of adult male and female rats. Brain Res. 935 (1-2), 73-80.

Zhang, D., Yang, S., Yang, C., Jin, G., Zhen, X., 2008. Estrogen regulates responses of dopamine neurons in the ventral tegmental area to cocaine. Psychopharmacology 199 (4), 625-635.

Zhou, J., Jia, C., Feng, Q., Bao, J., Luo, M., 2015. Prospective coding of dorsal raphe reward signals by the orbitofrontal cortex. J. Neurosci. 35 (6), 2717-2730.

Zhou, W., Cunningham, K.A., Thomas, M.L., 2002. Estrogen regulation of gene expression in the brain: a possible mechanism altering the response to psychostimulants in female rats. Mol. Brain Res. 100 (1-2), 75-83.

Zsido, R.G., Villringer, A., Sacher, J., 2017. Using positron emission tomography to investigate hormone-mediated neurochemical changes across the female lifespan: implications for depression. Int. Rev. Psychiatry 29 (6), 580-596.

Zurkovsky, L., Brown, S.L., Boyd, S.E., Fell, J.A., Korol, D.L., 2007. Estrogen modulates learning in female rats by acting directly at distinct memory systems. Neuroscience 144 (1), 26-37. 